This PDF is a selection from a published volume from the National Bureau of Economic Research

Volume Title: Measuring and Modeling Health Care Costs

Volume Author/Editor: Ana Aizcorbe, Colin Baker, Ernst R. Berndt, and David M. Cutler, editors

Volume Publisher: University of Chicago Press

Volume ISBNs: 978-0-226-53085-7 (cloth); 978-0-226-53099-4 (e-ISBN)

Volume URL: http://www.nber.org/books/aizc13-1

Conference Date: October 18-19, 2013

Publication Date: February 2018

Chapter Title: Risk Adjustment of Health Plan Payments to Correct Inefficient Plan Choice from Adverse Selection

Chapter Author(s): Jacob Glazer, Thomas G. McGuire, Julie Shi

Chapter URL: http://www.nber.org/chapters/c13122

Chapter pages in book: (p. $379-418)$ 


\title{
Risk Adjustment of Health Plan Payments to Correct Inefficient Plan Choice from Adverse Selection
}

\author{
Jacob Glazer, Thomas G. McGuire, and Julie Shi
}

\subsection{Introduction}

In the United States and a number of other countries, individuals choose health insurance from among competing health plans. The Affordable Care Act (ACA) mandates previously uninsured individuals choose a plan offered in the new state-level health insurance exchanges (now sometimes referred to as "marketplaces"). Parts C (managed care plans) and D (drug plans) in Medicare use private health insurance markets, as do the national health care systems of the Netherlands, Germany, Switzerland, and other countries. A fundamental premise of payment regulation in all of these markets is that plans' revenue should be "risk adjusted" to account for cost differences among enrollees. Risk adjustment protects plans and mitigates incentives related to adverse selection. The risk-adjustment formulas can be complicated, as they are in the ACA where they involve demographics, scores of diagnostic variables, and interactions. Weights on risk-adjusted variables, like age or diagnoses for certain conditions, are generally derived from regression-based statistical procedures on data sets with millions of people.

Jacob Glazer is professor of economics at Tel Aviv University and at the University of Warwick. Thomas G. McGuire is professor of health economics at Harvard Medical School and a research associate of the National Bureau of Economic Research. When this chapter was written, Julie Shi was a postdoctoral fellow at Harvard Medical School. She is currently assistant professor of economics at Peking University.

Research for this chapter was supported by the National Institute of Mental Health (R01 MH094290) and the National Institute of Aging (P01-AG032952). This chapter was prepared for presentation at the NBER Conference, "Measuring and Modeling Health Care Costs,"October 18-19, 2013, in Washington, DC. We are grateful to Randy Ellis, Amy Finkelstein, Jonathan Kolstad, Tim Layton, Karen Stockley, Aaron Schwartz, and a referee for comments on a previous version. For acknowledgments, sources of research support, and disclosure of the authors' material financial relationships, if any, please see http://www.nber.org/chapters/c13122.ack. 
A well-known limitation of risk-adjustment methods is that the weights are sometimes estimated from data not from the plans paid by risk adjustment. For example, in Medicare, private managed care plans are paid with a risk-adjustment system estimated with data from beneficiaries who elect not to join one of the private plans. In the new exchanges, the risk-adjustment formulas the federal government recommends are estimated from employees of large employers and their dependents, individuals generally not eligible to participate in exchanges.

The issue is partly practical and temporary in the sense that once data from exchanges accumulate or Medicare private plans report more complete data, weights can be recalculated based on the "real data." But there is a more fundamental problem access to data does not solve: statistical procedures make risk-adjustment weights a function of the data, and, economic equilibrium makes the data a function of the risk-adjustment formula. In other words, the risk distribution of individuals who choose to join a plan, and even the services a plan decides to offer to its enrollees, are a function of how plans are paid. This is more than a technical concern-equilibrium effects on enrollment and services are precisely the adverse-selection problems risk adjustment is designed to avoid. ${ }^{1}$

This chapter develops and implements a statistical methodology to account for the equilibrium effects (aka adverse selection) in design of a riskadjustment formula in health insurance markets. We focus on the "EinavFinkelstein" form ${ }^{2}$ of adverse selection in which enrollees sort between plans with fixed benefit offerings as a function of the plans' premiums. Because these premiums do not reflect each person's marginal costs, the plan with the better coverage tends to be a bargain for the sick and too expensive for the healthy, leading some people to choose the wrong plan. ${ }^{3}$ We show that risk adjustment affects the equilibrium sorting, and can be used to improve upon the adverse-selection outcome. We find the "second-best" allocation between plans, second best meaning the most efficient that can be achieved given the premium categories available, and then show how choice of risk adjustors can attain this second-best outcome.

Section 12.2 reviews the literature, highlighting recent papers by Einav and Finkelstein (EF) that study enrollee sorting between plans with fixed characteristics charging the same premium to all enrollees. Section 12.3

1. Another way to say this: if risk adjustment did not affect enrollment and/or services offered, there would be no need to risk adjust. The law of large numbers would deal with any plan-level risk.

2. For example, Einav and Finkelstein (2011), Einav, Finkelstein, and Levin (2010), and Einav, Finkelstein, and Cullen (2010).

3. Major precursors of the Einav-Finkelstein paper are Cutler and Reber (1998) who studied sorting in the benefit plans at one employer, and before that and more generally, Akerlof (1970). The second form of adverse selection in health insurance markets stems from Rothschild and Stiglitz (1976) in which plan offerings are not fixed and plans distort benefit offerings to attract less costly enrollees. Glazer and McGuire (2000) used the Rothschild-Stiglitz model to draw the implications for risk adjustment in health insurance. 
incorporates risk adjustment into the $\mathrm{EF}$ framework, oriented around the working of the ACA. We retain the EF assumption that there are two plan types (which we call Silver and Gold) with fixed characteristics and build on EF in a number of ways: in addition to introducing risk adjustment, we allow for many premium categories (for example, premiums conditioned on age). We also incorporate an explicit model of selection in which individuals choosing between plan types make imperfect forecasts of their future health care costs. The nature of adverse selection is critical to efficiency interpretations of an EF model. The fundamental normative implication of the EF model is that when a more generous plan experiences adverse selection, the "Gold plan" premium should be subsidized to encourage more enrollment than would occur in competitive equilibrium. We show (a) the optimal subsidy should correct for individuals' imperfect forecasts in addition to the "marginal-average cost gap" in the EF model, (b) the resulting allocation minimizes but does not eliminate inefficiencies in sorting (i.e., is a second best), and (c) the optimal subsidy can be achieved by risk adjustment.

Section 12.4 implements the theoretical ideas with data from seven years of the Medical Expenditure Panels Survey (MEPS), drawing a population representative of those eligible for exchanges in the ACA. Operationalizing the model from section 12.3 requires simulating the payment system in exchanges, specifying costs in the Gold and Silver plans, and specifying the underlying demand (selection) behavior. Importantly, the regulator needs to know the nature of the inefficiency due to selection in order to design the right risk-adjustment system to correct the inefficiency.

Empirical results are contained in section 12.5 where we evaluate several equilibria in terms of the efficiency of plan sorting and in the degree to which the payment system associated with risk adjustment "fits" costs at the Silver and Gold plans (in equilibrium). We start with no risk adjustment where premiums for twelve age-geography categories are determined in equilibrium between competing Gold and Silver plans. The welfare loss from sorting is high and the fit of plan costs is poor. Conventional risk adjustment, of the type proposed in the ACA, improves sorting and improves the fit of play payments to cost. We then show how a modification of conventional riskadjustment methods can set risk-adjustment weights so that in equilibrium, the incremental premium for the Gold plan leads to the efficient (second-best) sorting. The method is constrained regression, where the constraints (on the risk-adjustment weights) require that risk adjustment transfer sufficient funds to the premium group to achieve the desired subsidy in equilibrium.

\subsection{Background and Literature Review}

A foundation of the policy of managed competition, and of the many regulated health insurance markets based on the idea, is that consumers choose among competing health plans in the presence of prices that reflect 
the additional costs of more versus less generous plans. In the US Medicare program, for example, competing private health plans can add benefits over the required minimum but must finance these by higher premiums. The ACA creates an ordered set of plans designated Bronze, Silver, Gold, and Platinum with more coverage for higher prices.

Consumer utility maximization leads to efficient sorting among plans if consumers face premiums that present them with the "incremental cost" of benefits in the more generous plan (Keeler, Carter, and Newhouse 1998). The argument is the same as that for prices generally: when consumers face prices equal to costs, net utility equals social welfare and consumers make efficient choices. The problem is that managed competition does not deliver the required incremental prices (Bundorf, Levin, and Mahoney 2012; Glazer and McGuire 2011). When the product is health insurance, incremental cost is person-specific. In other words, the incremental cost across two plans differs for each person depending on their expected health care costs. Asymmetric information between plans and enrollees interferes with efficient pricing. Furthermore, managed competition policies purposefully limit the degree to which plans may price discriminate based on observables related to health care costs. Higher premiums for those with previous illnesses are, for example, nearly universally prohibited. (The ACA also has age-band restrictions.)

Managed competition policies rely on risk adjustment of payment to plans in order to pay more for higher-cost enrollees. While this deals with some aspects of efficient plan service provision, it may not help at all with consumer sorting among plans. Our main objective in this chapter is to study how risk-adjustment payments schemes, set by a regulator, can affect the premiums that plans charge enrollees, which in turn will affect enrollees' choice of plans and, hence, welfare. We build on the model introduced in a series of papers by Einav and Finkelstein, primarily the well-known version in Einav, Finkelstein, and Cullen (2010). We will refer to the model as the "EF" model, and review its basics here.

The EF model shows how to measure the welfare losses due to adverse selection using demand and cost curves. Einav, Finkelstein, and Cullen (2010) outline a stylized version of their approach and discuss its application in different settings. In what they refer to as their "textbook example," consumers choose between a high-coverage contract, $H$, and a low-coverage contract, $L$. In their example the $L$ contract refers to no insurance and, hence, it is costless to all consumers and is free. The (incremental) price of the $H$ contract is denoted by $p$ paid by all potential enrollees, and consumers purchase the $H$ contract if their valuation of it, net of the price $p$, exceeds their valuation of the low contract, normalized to zero. As premium falls, new enrollees choose $H$, defining an average and marginal cost curve. For a given price $p$, average cost for plan $H$ (denoted by $A C(p))$ is the expected costs of the enrollees, who (endogenously) choose to enroll in contract $H$, 


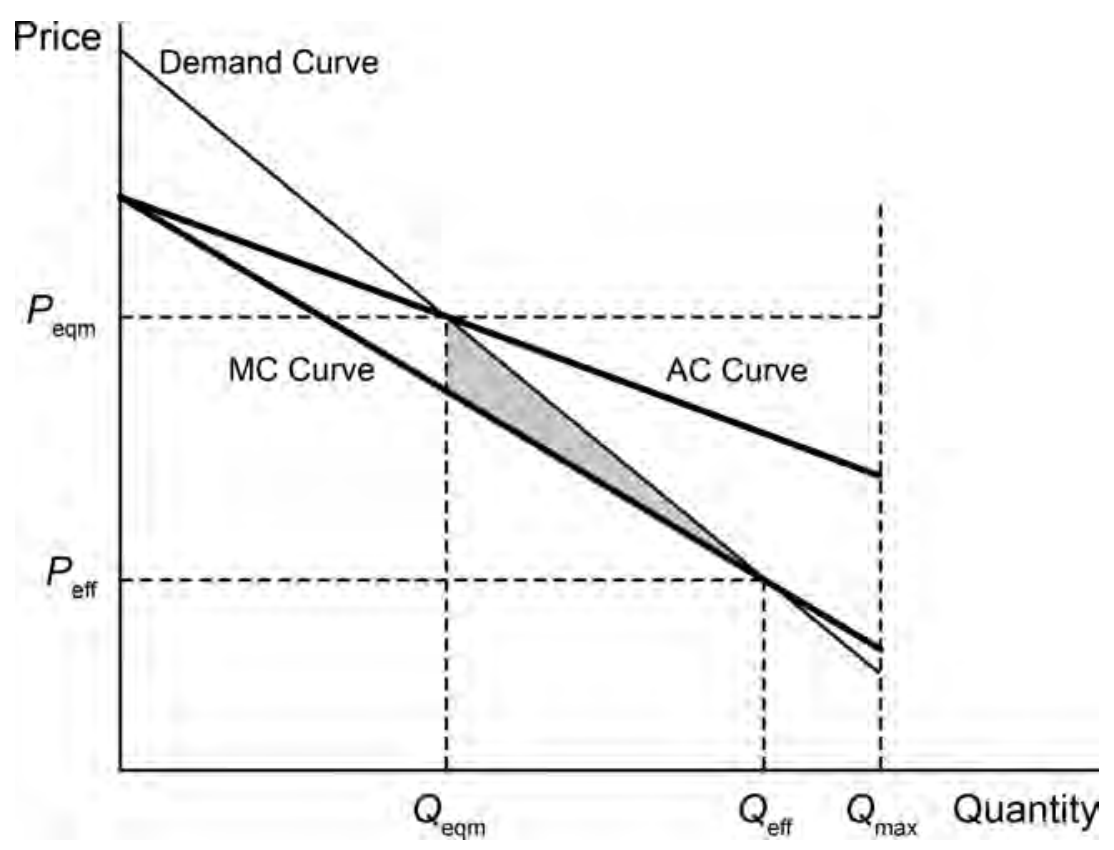

Fig. 12.1 Efficiency costs of adverse selection in Einav-Finkelstein model Source: Einav, Finkelstein, and Cullen (2010).

divided by the number of individuals who purchase it. For a given price $p$, marginal cost (denoted by $M C(p)$ ) is the expected cost for the individual(s) whose willingness to pay is exactly $p$. See figure 12.1, a replica (omitting some labeling) of figure 1 in Einav, Finkelstein, and Cullen (2010).

In market equilibrium, insurers are assumed to price competitively, such that $p=A C(p)$. As in a standard welfare analysis, consumer surplus for a given individual in the high contract is measured by their willingness to pay for the $H$ contract minus the price, and producer surplus for a given individual is measured by price minus the cost of that individual. The efficient price (premium) and quantity (enrollment in $H$ ) are given by the point where the marginal cost intersects demand, and the equilibrium price and quantity are given by the point where the average cost intersects demand. The efficiency loss, in their setting, is given by the "conventional" welfare triangle bounded by the marginal cost and demand curve, between the efficient quantity and the equilibrium one (the shaded area in figure 12.1). ${ }^{4}$ In their

4. There are two cases, the "adverse selection" case, where individuals' willingness to pay for plan $H$ is increasing with their cost (to the plan) and the other, the "advantageous selection" case, where individuals' willingness to pay cost is decreasing with their cost. In the adverse selection case, the one shown in figure 12.1 and the one we work with in this chapter, the welfare loss is due to the fact that "too few" individuals join the $H$ plan, relative to social optimum. 
empirical application using data on insurance choices and costs from a large employer, Einav, Finkelstein, and Cullen detect adverse selection, but they estimate the welfare costs of adverse selection to be small. ${ }^{5}$

We modify and extend the basic EF model in several ways to further illuminate properties of markets with insurance choice. ${ }^{6}$ The first has to do with the relationship between willingness to pay and costs. In the "textbook case," the ordering in willingness to pay of those who join as a function of $p$ is matched by a one-to-one ordering of falling costs. As was acknowledged by Einav, Finkelstein, and Cullen (2010), if individuals' costs are not monotonically increasing or decreasing with willingness to pay, as generally they will not be, then the point where marginal cost intersects the demand will not be first best and the welfare triangle in figure 12.1 will not describe the welfare loss. ${ }^{7}$ The reason is that with heterogeneity in the relationship between demand and incremental cost, "marginal cost," $M C(p)$ is, in fact, an average of the marginal costs over all individuals whose willingness to pay is exactly $p$. Thus, even when $M C(p)=p$, there are individuals (those whose willingness to pay is higher than $p$ but their cost is higher than their willingness to pay) who join the plan even though, from a social point of view, they should not, and there are individuals (those whose willingness to pay is less than $p$ but their cost is lower than their willingness to pay) who will choose not to join the plan even though, from a social point of view, they should. Another way to say this is that only in the very special circumstances assumed in the textbook version of the EF model is a single premium (equal to $M C$ ) able to eliminate welfare loss from sorting. ${ }^{8}$ In general, the situation will be as depicted in figure 12.2. Two groups (here 1 and 2) have different incremental marginal costs and demand, but must share a common incremental premium $(\Delta p)$. Any $\Delta p$ is associated with welfare losses. The second-best analysis we perform later essentially seeks to minimize the sum of the losses, $L_{1}$ and $L_{2}$ in the figure, as a function of the incremental premium. An example of the welfare losses that will emerge with heterogeneity is that under the ACA, plans cannot discriminate in premium across

5. The authors also discuss how the welfare losses (gains) from imperfect competition or discriminatory prices can be quantified. They also compare the estimated welfare loss to the social cost of subsidized prices or mandates.

6. Kolstad and Kowalski (2014) use a modification of the Einav, Finkelstein, and Cullen (2010) model to study the reduction in adverse selection as a result of an "individual mandate" in the recent reform in Massachusetts.

7. See their footnote 3 .

8. This point is emphasized by Bundorf, Levin, and Mahoney (2012). Commenting on analyses that imply a single premium can efficiently sort a population between two plans, they observe, "These analyses, however, assume perfect correlation between enrollee risk and preferences for coverage and make strong assumptions about the relationship between preferences and plan costs. We show that if these assumptions are violated, a uniform contribution policy (i.e., a policy under which individuals face the same prices for the plans) cannot induce efficient consumer choices." (3215). Glazer and McGuire (2011) show that in general a single-premium policy cannot lead to efficiency. 


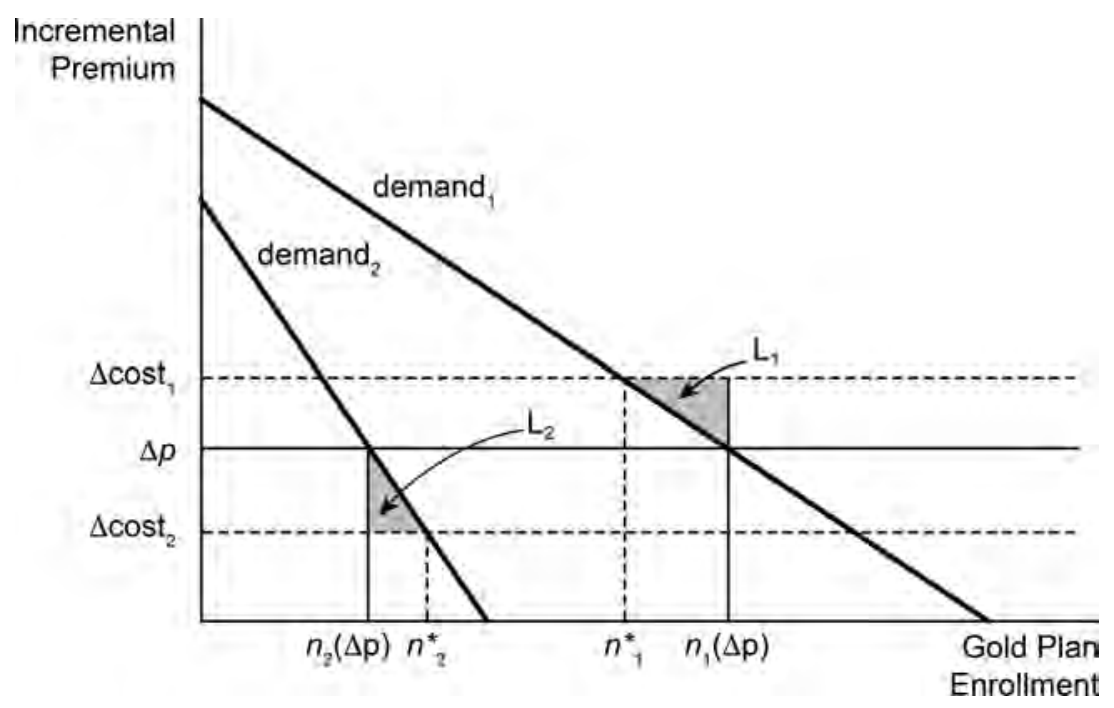

Fig. 12.2 Welfare loss with a common incremental premium

individuals with different health status or other characteristics that may affect their costs. In our analysis we allow for individual heterogeneity at the margin in our welfare analysis. ${ }^{9}$

Second, we consider a "real" alternative plan and take account of what is happening in equilibrium for this plan as the distribution of risks shifts in response to changes in the incremental premium for the high-coverage (Gold) plan. When the "other plan" is not a zero-cost plan, the average costs and equilibrium premium in that plan also change as demand changes for the Gold plan. This modifies the interpretation of the EF textbook diagram and is essential in any empirical application to a multiple-plan context.

Third, we allow for individuals' willingness to pay for a plan to differ from their (social) benefit from that plan. ${ }^{10}$ If, for example, individuals are not fully informed about their health cost risk, or cannot fully understand their risks, they will not accurately anticipate the services they will receive upon joining a particular plan. They may over- or underestimate how much they have to gain from joining the $H$ plan. This issue is tied to adverse selection, because it is just this anticipation that drives the higher-cost people to join the $H$ plan. As long as this process is imperfect, that is, the anticipation is

9. Spinnewijn (2017) considers a different explicit model of selection in which "demand frictions" introduce heterogeneity and affect choice. He also finds that the welfare economics of the standard selection model are altered.

10. See Abaluck and Gruber (2011) for an example of an analysis of "mistakes" in buying health insurance made by the elderly in choosing their drug plans in Medicare. 
only partial, then consumers will make "mistakes" in their plan choice. In such a case, demand and marginal benefit curves do not generally coincide and even if price is equal to marginal cost, equilibrium will not be socially efficient.

Fourth, we enrich the payment system studied and introduce multiple premium categories and risk adjustment. In the ACA, plans can discriminate on the basis of age (within limits), geography, and smoking status. Furthermore, risk adjustment will move funds to plans drawing a sicker population, affecting equilibrium premiums and consumer sorting. We explicitly incorporate the effect of risk adjustment within an EF model, and show that an appropriately designed risk-adjustment payment scheme may reduce welfare losses associated not only with EF adverse selection, but also with individuals' inability to perfectly evaluate the services they will receive if they join a plan.

Our chapter is also related to a number of other recent papers that have studied the welfare implications of policy changes or changes in the market conditions in the health insurance market. A comprehensive review of this emerging literature is contained in Einav, Finkelstein, and Levin (2010). Recent papers have specified more complete models of consumer preferences to enable a more thorough normative interpretation of market outcomes. These models allow authors to quantify the magnitude of welfare losses from, among other things, distortionary pricing (see Bundorf, Levin, and Mahoney 2012; Carlin and Town 2010; Geruso 2012; Handel, Hendel, and Whinston 2013), restrictions on the choice set (see Lustig 2008; Dafny, Ho, and Varela 2013; Lucarelli, Prince, and Simon 2012), and changes in the allocation of consumers to plans (see Handel 2013; Lustig 2008).

\subsection{Risk Adjustment to Fix Adverse Selection}

This section presents a model of a health insurance market with regulated benefits and two types of competing plans that we refer to as Silver plans and Gold plans. Enrollees face premiums and choose a plan. We allow multiple premium categories and risk adjustment. Our risk-adjustment system pays the same for an individual independent of what plan they join. ${ }^{11}$ As in the standard EF model, we describe equilibrium and efficient sorting between plan types, and identify the efficient incremental premium for the Gold plan for each premium category.

11. The model captures features of the managed competition approach to individual health insurance, which serves as the intellectual basis of ACA exchanges, Medicare Parts C and $\mathrm{D}$, and health policy in a number of European countries. Premium subsidies are a feature of all of these policy contexts. Incremental premiums (the difference between Gold and Silver) govern sorting and efficiency so we can be agnostic about whether there are subsidies for the basic plan type. Our approach is also consistent with "premium-support" policies awarding a risk-adjusted voucher to enrollees who can apply the voucher toward premium at any plan. 


\subsubsection{Costs and Demand for Health Plan Alternatives}

The $N$ people in an insurance pool vary in two observable dimensions, according to health status, the basis of risk adjustment, and according to another set of characteristics, the basis of premiums. Health status is indexed by $h, h=1, \ldots, H$; premium characteristics are indexed by $t, t=1, \ldots, T$. Each categorization is mutually exclusive so that a person is characterized by an $(h, t)$ pair. There can be overlap between the factors (e.g., age might be a used in both $h$ and $t$ ), but there is some independent information about health care costs in each of $h$ and $t$. For example, geography might be used as a basis for premiums but not risk adjustment, and prior health conditions might be a basis for risk adjustment but not premiums. We will refer to a person with characteristics $h$ and $t$ as a person of type $h t ; N_{h t}$ is the number of people of type $h t$ in the population and $N_{t}$ is the number of people with premium type $t .{ }^{12}$

Plans provide services, $x$, according to $h$ and $t$, and services a person of type $h t$ would get are fixed in each plan. Gold is more generous so that $x_{h t}^{g}>x_{h t}^{s}$ for all $h t$, with $x$ measured in dollars; $x_{h t}^{g}$ and $x_{h t}^{s}$ are thus also the costs of serving a person of type $h t$ in the Gold and Silver plans, respectively. Define the incremental costs for a person of type $h t$ as $x_{h t} \equiv x_{h t}^{g}-x_{h t}^{s}$. For simplicity in presentation, we let incremental cost $x_{h t}$ represent both social incremental cost and plan incremental cost, implying that the out-of-pocket costs to an $h t$ type are the same in Silver and Gold. ${ }^{13}$

Although every member of type $h t$ gets the same increment in services going from Silver to Gold, individuals are heterogeneous in their valuation of Gold over Silver plans. Demand is $n_{h t}\left(p_{t}\right)$, the number of people among type $h t$ who choose to enroll in the Gold plan as a function of the incremental premium for members of this premium type, where the incremental premium is the difference between the Gold and Silver plan premiums for that premium group: $p_{t} \equiv p_{t}^{g}-p_{t}^{s}$. Heterogeneity in demand could be due to tastes for health care services, risk aversion, or other preferences regarding cost management methods in the two plans. As in EF, our normative framework includes these preferences as a component of welfare. We assume demand is downward-sloping: $n_{h t}^{\prime}\left(p_{t}\right)<0$. The Gold plan's "aggregate" demand function of individuals in premium category $t$ sums enrollment demand over the $h$ categories:

$$
n_{t}\left(p_{t}\right)=\sum_{h} n_{h t}\left(p_{t}\right)
$$

12. A similar model of plan costs is used in McGuire et al. (2013) for one plan type. That paper shows how to choose risk-adjustment weights when premiums also contribute to fit but the premiums are determined in market equilibrium.

13. Premiums, of course, will differ between plans. In exchanges, Gold plans have more coverage, so part of more services would be due to moral hazard in demand. Keeping track of out-of-pocket differences would complicate the presentation of the accounting in this chapter without adding insight. 
The corresponding "inverse" demand function of each $h t$ type is $p_{h t}\left(n_{h t}\right)$, and the "inverse" aggregate demand, $p_{t}\left(n_{t}\right)$.

"Demand" can be distinct from "benefit" in the context of selection and insurance choice. Selection is driven by consumers being able to anticipate their health care costs, but they do so imperfectly. Consumers are therefore also generally imperfect in their anticipation of how much they would benefit from membership in alternative health insurance plans, introducing a distinction between what consumers anticipate in terms of benefits and what they actually get in terms of benefits of plan choice. Demand is based on what consumers anticipate ex ante, whereas welfare is naturally based on ex post benefits.

\subsubsection{Efficiency}

When enrollees know their type $h t$ and face incremental premiums equal to the incremental cost, $x_{h t}$, their utility-maximizing choice of plan type achieves efficient sorting. However, since incremental premiums can be conditioned only on $t$ and not on $h$, first-best sorting between Gold and Silver plans is generally impossible. With the first-best unattainable, we characterize the premiums that minimize the welfare loss from inefficient sorting, assuming that people know their type, and subject to the constraint that premiums must be the same for all persons with the same $t$.

For a premium group $t$, the common incremental premium that maximizes social welfare solves the following problem:

$$
\operatorname{Max}_{p_{t}} \sum_{h}\left[\int_{0}^{n_{h l}\left(p_{t}\right)} p_{h t}\left(n_{h t}\right) d n_{h t}-n_{h t}\left(p_{t}\right) x_{h t}\right] .
$$

Recall that $n_{h t}\left(p_{t}\right)$ is the demand function of the $h t$ types and $p_{h t}\left(n_{h t}\right)$ is its inverse. When consumers know their type demand has the conventional interpretation as willingness to pay or consumer surplus, $x_{h t}$ is the cost of an individual of type $h t$ moving from Silver to Gold.

Assuming an interior solution (members from all $h$ groups are in both the Gold and Silver plans), the solution to equation (2) is $p_{t}^{*}$ :

$$
p_{t}^{*}=\frac{\sum_{h} n_{h t}^{\prime}\left(p_{t}^{*}\right) x_{h t}}{\sum_{h} n_{h t}^{\prime}\left(p_{t}^{*}\right)} .
$$

We state this result formally:

Proposition 1: Assuming demand indicates benefit, the welfare-maximizing incremental premium for premium group tequals the Gold plan's incremental cost averaged over the h groups joining the plan.

Proposition 1 extends the EF result by showing that the incremental premium should equate (averaged) incremental marginal cost to demand even when there is heterogeneity in the mix of persons joining Gold as a function of premium. 
The EF analysis and Proposition 1 share the important assumption that individuals can accurately forecast their expected cost. When this is not true, Proposition 1 must be modified. Equating incremental marginal cost to marginal benefit is then not the same as equating marginal cost to demand. The efficient second-best premium must also correct for the gap between expected and actual benefit of joining Gold.

\subsubsection{Equilibrium with Risk-Adjusted Payments and Selection}

Equilibrium consists of premiums for each of the $T$ premium categories for the Silver and Gold plans, and of an allocation of enrollees across the plan types. The equilibrium will be a function of the risk-adjustment formula. Let $r_{h}$ denote the risk-adjustment payment that (Gold or Silver) plans receive for each individual of type $h$. Suppose, as in exchanges, the riskadjustment system is financed by premium payments of enrollees. We can regard a plan paying into a risk-adjustment fund a constant amount for each enrollee, perhaps, as here, set equal to costs at the Silver plan averaged over the entire population, $\bar{x}^{s}$. The plan (either Gold or Silver) then receives $r_{h}$ back from the fund for each person of type $h$ joining the plan. The riskadjustment system is balanced budget if $\Sigma_{h} N_{h} r_{h}=N \bar{x}^{s}$. Plans must charge premiums that cover costs (after risk adjustment) according to each $t$ group. (The "budget constraint" for risk adjustment, $\bar{x}^{s}$, could be set at some other level, affecting the equilibrium premiums plans must charge.)

The premium for the Silver plan for type $t$ is $p_{t}^{s}$. We can write the Gold plan premium as $p_{t}^{s}+p_{t}$, the Silver plan premium plus the incremental premium for group $t$. Risk adjustment is set the by a regulator, and premiums are determined in market equilibrium. We assume that competition drives the profit for Silver and Gold plans to zero for each premium group. Thus, for each $t$ we have two zero-profit conditions:

$$
\begin{gathered}
\sum_{h}\left(r_{h}-\bar{x}^{s}+p_{t}^{s}-x_{h t}^{s}\right)\left(N_{h t}-n_{h t}\left(p_{t}\right)\right)=0, \\
\sum_{h}\left(r_{h}-\bar{x}^{s}+p_{t}+p_{t}^{s}-x_{h t}^{g}\right) n_{h t}\left(p_{t}\right)=0,
\end{gathered}
$$

where $N_{h t}-n_{h t}\left(p_{t}\right)$ is the number of individuals of type $h t$ in the Silver plan, and $n_{h t}\left(p_{t}\right)$, defined in equation (1) above, is the number in the Gold plan.

Conditions (4) and (5) incorporate utility maximization as well as competitive equilibrium among plans and thus describe a complete equilibrium in the insurance market, given a risk-adjustment system with weights, $r_{h}$.

\subsubsection{Risk-Adjustment Weights That Achieve (Second-Best) Efficient Sorting}

The $2 T$ equations in (4) and (5) describe a relationship between the riskadjustment weights, $r_{h}$, and the equilibrium premiums, $p_{t}$. The idea is to take 
this relationship into account when deciding risk-adjustment policy; specifically, to set the weights, $r_{h}$, so that the equilibrium premiums hit the desired target. When demand represents benefit, risk-adjustment weights that achieve efficient sorting in equilibrium satisfy equation (3), subject to equations (4) and (5). Each of the $T$ premium categories generates an equation describing the condition for second-best $p_{t}$ and a pair of zero-profit conditions. Substituting the equations for premiums, (4) and (5), into the efficiency condition (3) yields equation in the risk-adjustment weights, $r_{h}$. After these substitutions, there are $T$ equations. The "unknowns" are the $H$ risk-adjustment weights, $r_{h}$. In general there are relatively few premium categories in individual health insurance markets (e.g., age categories), and many risk-adjustment weights (age, gender, many diagnostic conditions). We refer to a set of weights that solve the $T$ equations for efficiency as $r_{h}^{s b}$.

With $T \ll H$, as is typical (in the standard EF model, $T=1$ ), there are many $r_{h}^{s b}$ solutions. How should we pick among these many alternatives? The luxury of multiple solutions allows pursuit of a second criterion in the choice of weights, the fit of the payment system, which, in the case of both MA and marketplaces, consists of a risk-adjustment system and enrollee premiums. Assessing and maximizing fit in a particular institutional context requires incorporation of payment rules, and data, both of which are introduced next.

\subsection{Empirical Application: Gold Plan Incremental Premiums and Risk Adjustment}

We draw an "exchange population" from the Medical Expenditure Panel Survey (MEPS) to implement the efficient (second-best) incremental premiums. Risk-adjustment weights are set by a regulator; premiums are determined in market equilibrium. Taking advantage of the multiple solutions available via risk adjustment, we use constrained regression methods to find the risk-adjustment weights that do the best job of fitting plan payments to costs subject to achieving the efficient incremental premiums. Our purpose is to develop and illustrate the application of a method for using risk adjustment to correct for selection problems. We model key features of exchanges - the population, the plans, the premium, and risk adjustment with MEPS data.

\subsubsection{Data and the Exchange Population}

The MEPS is a nationally representative survey of the civilian noninstitutionalized US population conducted annually since 1996. Each year MEPS collects information on approximately 33,000 individuals, enlisting a new panel of respondents followed for two years. Data are collected in five rounds of interviews covering the two-year period. The Household Component (HC) is the source for personal and household characteristics, including 
insurance coverage and self-reported health and health conditions. The HC is also the source of data on medical "events" (e.g., an inpatient stay or office visit) including information about diagnoses, procedures, and payments from various sources. The HC data are supplemented with information from the Medical Provider Component (MPC), based on phone surveys of hospitals, physician offices, pharmacies, and home health agencies. We use data from 2004 through 2010. The MEPS data understate health expenditures (Sing et al. 2006; Aizcorbe et al. 2012; Zuvekas and Olin 2009). We follow the correction proposed by Zuvekas and Olin (2009) to inflate total expenditures by a factor of 1.09 for individuals with an inpatient claim and by a factor of 1.546 for all other claims. ${ }^{14}$

We select a population of adults who would be eligible to enroll in state-level exchanges under current law based on their income, insurance, and employment status. We identify nonelderly individuals (ages nineteen to sixty-four) in households earning at least 138 percent of the federal poverty level. ${ }^{15}$ We select those who live in a household where an adult is ever (in either year) uninsured, a holder of a nongroup insurance policy, self-employed, employed by a small employer, or paying an out-of-pocket premium for their employer-sponsored health insurance (ESI) plan that is deemed to be unaffordable (as defined in the ACA) ${ }^{16}$ We include both years of data for a person who would qualify for exchanges in either year of the data, with the idea that these individuals are vulnerable to loss of insurance and share the same distribution of health care costs as persons who would enroll in the exchanges. In total, we have 64,667 person years. ${ }^{17}$ Children may also be in the exchanges, but since they are paid with a separate riskadjustment system, we confine the analysis here to adults.

Table 12.1 summarizes some statistics on this group. The population contains a relatively high proportion of Hispanics and lives disproportionately in the South. The education and income range is large because we include persons who may have health insurance, but in the individual or small-group

14. The MEPS surveys the "noninstitutionalized" population and underrepresents persons in nursing homes or with very long hospital stays. This also contributes to underreporting average medical expenses, but has a small effect on an exchange population.

15. Annual household income from each year is inflated to 2010 dollars using the Consumer Price Index (CPI-U) published by the Bureau of Labor Statistics, and we apply 2009 federal poverty guidelines for the forty-eight contiguous states (available online at http://aspe.hhs .gov/poverty/09poverty.shtml). We follow the methodology of the Kaiser Family Foundation that uses these income criteria to select the population eligible to purchase insurance through an exchange (Trish et al. 2011). Adults and children in households with lower incomes are deemed to qualify for Medicaid. We do not simulate employer behavior as does the CBO model (CBO 2011).

16. Small employers are either (a) those with fewer than fifty employees or (b) those with fewer than 100 employees and who report only one business location. The ACA states that individuals whose out-of-pocket premiums for employer-sponsored insurance exceed 9.5 percent of family income will be eligible to purchase health insurance through an exchange.

17. Most people contribute two years of data. If someone dies in the first year, they would contribute just one. We used no additional weighting of observations. 
$\%$

\section{Age}

$19-30$

30.0

$31-50$

46.1

$51-64$

23.7

Male

50.4

Race

White, non-Hispanic

Black, non-Hispanic

13.7

Hispanic

Asian

Other

Education

Less than high school

17.9

High school

Some college

17.4

College degree

29.4

Employment status

Continuously employed

74.6

Continuously unemployed

11.7

Household income (\$2010)

Mean

$\$ 32,660$

$<\$ 25,000$

48.7

$\$ 25,000-50,000$

32.5

$\$ 50,000-100,000$

15.0

$>\$ 100,000$

Geographic region

Northeast

14.0

Mideast

19.4

South

38.2

West

28.3

Insurance status

Uninsured

55.6

Nongroup

ESI with employee premium $>9 \%$ of income

7.7

Self-employed

0.5

Small group ESI

32.5

Health care spending (mean, \$2010)

$\$ 2,648$

Self-reported health status

Excellent

Very good

Good

Fair

Poor

2.0

Source: Medical Expenditure Panel Survey (MEPS), 2004-2010. 
market. By in large, this is a relatively healthy population, with 60 percent rating their health Excellent or Very Good. Average health care spending from all sources was $\$ 2,648$ in 2010 dollars.

\subsubsection{Silver and Gold Plan Costs}

The ACA allows for four plan levels, Bronze, Silver, Gold, and Platinum (along with a high-deductible plan for young adults), distinguished by the "actuarial value" of coverage in each level. ${ }^{18}$ All so-called Qualified Health Plans (QHPs) must cover a set of mandated benefits, but are free to contract with networks of providers and to "manage" care. We assume two plan types, and exaggerate the difference between Gold and Silver. Specifically, we assume the costs in a Gold plan are to 120 percent of costs in a Silver plan, making incremental costs equal to 20 percent of Silver plan costs for each person. In the empirical application, we use MEPS data to classify exchange participants into $h t$ groups, and then assign the average costs within the group as Silver plan costs. We inflate the costs for each $h t$ group by 20 percent to assign Gold plan costs.

\subsubsection{Plan Revenues}

The ACA specifies that premiums be based on age (with regulated rate bands), smoking status, geography, and family size, but not on preexisting conditions, gender, or other factors. ${ }^{19}$ We set three age categories, young adult (nineteen to thirty), middle-age adult (thirty-one to fifty), and older adult (fifty-one to sixty-four), and four geographic areas, the four census regions (to mimic geographic areas within a state). We thus have twelve $(3 \times 4)$ premium categories for which we will study the incremental premium between Gold and Silver plans. We do not use smoking status because this variable, conditional on age, is weakly associated with health care costs in the exchange population..$^{20}$ For purposes of this analysis, we treat couples as two individuals. Rate-band regulation applies to the total premium at plans, not the incremental premiums. After risk adjustment, our equilibrium premiums satisfy ACA rate-band restrictions. $^{21}$

18. Actuarial value in the ACA is the share of covered costs paid by the plan. Bronze plans have an actuarial value of .6; Silver, .7; Gold, .8; and Platinum, .9. Deductibles and copayments/ coinsurance determine the actuarial value.

19. The CMS has recently recommended a particular age profile to be used in premiums, though states are free to set their own subject to the maximum 3-to-1 ratio between old and young (Department of Health and Human Services 2013).

20. We found this in our earlier paper on premiums and risk adjustment with these data (McGuire et al. 2013). Smoking status is problematic also from the standpoint of accurate reporting.

21. Our premium analyses ignore the temporary reinsurance features of exchanges. In the first three years of exchanges, plans will be forced to participate in a federally run system of reinsurance in which the "attachment point" where reinsurance kicks in is set at $\$ 60,000$. Plans are responsible for only 20 percent of costs after this point. Reinsurance could be incorporated by refiguring plan net costs with this feature as we have done in other research (Zhu et al. 2013). 
We risk adjust with the Hierarchical Condition Category (HCC) model recommended for exchanges by the Centers for Medicare and Medicaid Services (CMS) (Department of Health and Human Services 2013). A simpler version of this model pays private drug and managed care plans in Medicare. The exchange version maps diagnoses from ICD-9 codes from claims into one of $100 \mathrm{HCCs}$. Diseases within an HCC are similar clinically. Each individual is given a $(0,1)$ indicator for each HCC, and these become part of a linear regression model with individual demographics and some disease interactions to predict cost. The coefficients from this model are the "weights" on age, gender, HCC, and other factors used in risk adjustment (Pope et al. 2011). We use the same age categories for risk adjustment as the CMS-HCC model. Our goal is to find the best weights on the elements going into the CMS risk-adjustment model.

Notably, CMS recommends that the HCC model for exchanges be concurrent, using this year's medical events to determine the risk-adjusted payment for this year. This is in contrast to its use in Medicare, and virtually all other formal risk-adjustment systems, where the model is prospective, using last year's medical experience to predict this year's costs. We follow CMSrecommended practice and use concurrent risk adjustment here. ${ }^{22}$

Our risk-adjustment model diverges from the CMS recommendation in several ways to accommodate the MEPS data. First, whereas the CMS-HCC model uses five-digit ICD-9 diagnosis codes to classify diagnoses, the MEPS public use files do not include five-digit ICD-9 codes. We use the three-digit ICD-9 codes, which are publicly available. ${ }^{23}$ Documentation of the CMSHCC model indicates that moving from three- to five-digit classification does little to improve model fit in MEPS. ${ }^{24}$ In MEPS, diagnostic data come from household reports that lack the specificity and precision of physician reports (AHRQ 2011). Second, we do not include the full set of HCC indicators because of limitations of our sample size, nor do we include interaction effects for the same reason. The fifty-eight HCCs with more than twenty observations are entered in the model. The remaining nine HCCs appearing in the

22. Concurrent risk adjustment has two things going for it: first, it does not require data from a previous year to figure; and second, it will do a much better job of fitting plan costs than prospective risk adjustment. The main problem with concurrent risk adjustment is that it weakens incentives for plans to contain costs (Van de Ven and Ellis 2000). Medicare has a version of the same problem as exchanges of how to pay for the "new" beneficiaries without a prior year of experience. For these new beneficiaries they use a simplified age-gender riskadjustment model. Exchanges could do the same.

23. In our model we assume that the three-digit code we observe in the data corresponds to the smallest ICD-9 code that starts with those three digits. For example, an ICD-9 code of 003 in MEPS is assumed to represent 0031 , which is the smallest code within the 003 category.

24. The MEPS documentation states: "DxCG Inc. staff have examined how using 3-digit diagnoses (rather than 5-digit codes) would affect the prospective DCG/HCC model's performance. They concluded that, although using 3-digit codes would reduce the model's specificity in clinical classification and its predictive accuracy, the loss in specificity and predictive power was small" (AHRQ 2008, C-2). 
data with a total of seventy-three observations are aggregated into a single category. The HCC classifications HCC108 (Chronic Obstructive Pulmonary Disease) and HCC 176 (Artificial Openings for Feeding and Elimination) are too inclusive with our three-digit classification, so we broke these into finer categories. We also added HCCs for pregnancy. The exact algorithm we used to modify the HCCs is described in table 12A.1 in the appendix. We will refer to the risk-adjustment system we use as CMS-HCCs, even though we modified it in the ways just described. Risk-adjustment regressions (conventional and constrained) are represented in table 12A.2 of the appendix.

\subsubsection{Demand for Gold Plan and Efficiency of Sorting}

We specify demand and efficiency in ways that can be operationalized empirically. Our assumptions respect important economic properties: first best is attained with full information and incremental premiums equal to incremental costs for all persons; no selection emerges when everyone has the same expectation about their health care costs; and, with limited premium discrimination, individuals' more accurate forecasting of their own costs increases selection.

Demand for the Gold plan depends on the benefits a person expects to get in Gold over Silver, and on the incremental premium. Efficiency depends on the added benefits a person actually gets in a plan, and on the incremental cost. We start with efficiency and assume the incremental benefit a person $i$ of type $h t$ gets in the Gold plan, $b_{i h t}$, has two components, both measured in dollars:

$$
b_{i h t}=\beta x_{h t}+v_{i}, \beta>1, v_{i} \sim \text { uniform }\left[v_{\min }, v_{\max }\right] .
$$

The first component of benefit is the value of incremental services type $h t$ gets in the Gold plan, $\beta x_{h t}$, common to all members of group $h t$. In what follows, we assume that all individuals share the same $\beta$. When $\beta>1$, these services are valued at more than cost $(\operatorname{cost}=1)$. ( $\beta$ could also be less than one.) Second is an idiosyncratic component of benefit that differs by person, $v_{i}$, which captures idiosyncratic valuation of the incremental services, risk aversion, taste for plan management styles, and other factors. We assume for simplicity, that $v_{i}$, is uniformly distributed between a minimum and maximum value, but the range $\left[v_{\min }, v_{\max }\right]$ depends on $t$.

For efficiency, a person should be in the Gold plan if and only if the incremental benefits of Gold exceed the incremental costs. Incremental costs in Gold are $x_{h t}$ so the rule for efficiency is that individual $i$ should be in Gold if:

$$
\beta x_{h t}+v_{i}-x_{h t}>0 \text {. }
$$

In relation to the first best, the welfare loss in any equilibrium is the lost benefits for those in the "wrong" plan. Generally, for a person in Silver when equation (6) is positive, the loss is $\beta x_{h t}+v_{i}-x_{h t}$; for a person in Gold when equation (6) is negative, the loss is $-\left(\beta x_{h t}+v_{i}-x_{h t}\right)$. 
Turning to demand, we specify what individuals expect in terms of incremental benefits at the Gold plan. Selection on the basis of health costs depends on individuals' ability to forecast their health care demand. ${ }^{25}$ Better forecasting aggravates selection incentives. We assume a person of type $h t$ expects the following incremental services in the Gold plan:

$$
x_{h t}^{e}=\gamma x_{h t}+(1-\gamma) \bar{x} .
$$

Individuals' expectations of their added services are a weighted average of their $h t$-group incremental cost, $x_{h t}$, and the population average, $\bar{x}$. The weight, $\gamma$, on $h t$-group specific spending in expectations could differ by person, but for simplicity we assume all persons share the same ability to predict. The case of "no selection" corresponds to $\gamma=0$; when $\gamma=1$, individuals fully anticipate their incremental services in the Gold plan. We operationalize $x_{h t}$ by the predicted values from a regression using all the $h$-variables from the CMS-HCC model as well as the $t$-variables used to define premiums. This regression is reported in table 12A.2 of the appendix.

Recalling that $p_{t}$ is the incremental premium charged to a person of type $t$ in a Gold plan, an individual $i$ chooses Gold if:

$$
\beta x_{h t}^{e}+v_{i}-p_{t}>0 \text {. }
$$

The equation (7) rule can be aggregated to define demand curves for Gold plan membership. Assuming an interior solution (i.e., the premium $p_{t}$ is such that some individuals choose the Gold plan and some choose the Silver plan) demand for membership in Gold for one $h t$ group is

$$
N_{h t}^{g}=\frac{v_{\max }-\left[p_{t}-\beta x_{h t}^{e}\right]}{v_{\max }-v_{\min }} N_{h t} .
$$

The nature of selection and efficiency in our EF-type model can be illustrated with demand curves for two $h$ groups of the same size with the same $t$ and therefore facing the same premium (see figure 12.3). We let $h$ take the values 1 and 2 and call the groups $1 t$ and $2 t$, with costs higher for group $1 t$. Demands for Gold for each group (from equation [8]) will be linear, with a slope of $\left[-1 /\left(v_{\max }-v_{\min }\right)\right] N_{h t}$, (which, in this example, is identical to both types). The intersection on the vertical axis will be where $p_{t}=v_{\max }+\beta x_{h t}^{e}$, taking a value higher for the higher-demand group. Since expectations of health care use are imperfect, actual benefits will diverge from expected benefits (demand). Suppose groups $1 t$ and $2 t$ both underestimate their actual incremental use in the Gold plan. Benefits are also shown in figure

25. Selection could also arise based on another factor correlated with health care costs. Correlation with "other factors" is why in some settings researchers observe favorable selection. (See, e.g., Cutler, Lincoln, and Zeckhauser 2010.) For example, if risk aversion is inversely related to health care costs, more generous plans will experience favorable selection. Here we set $v_{i}$, representing "other factors," to be independent of health care costs so no such correlations are introduced. 


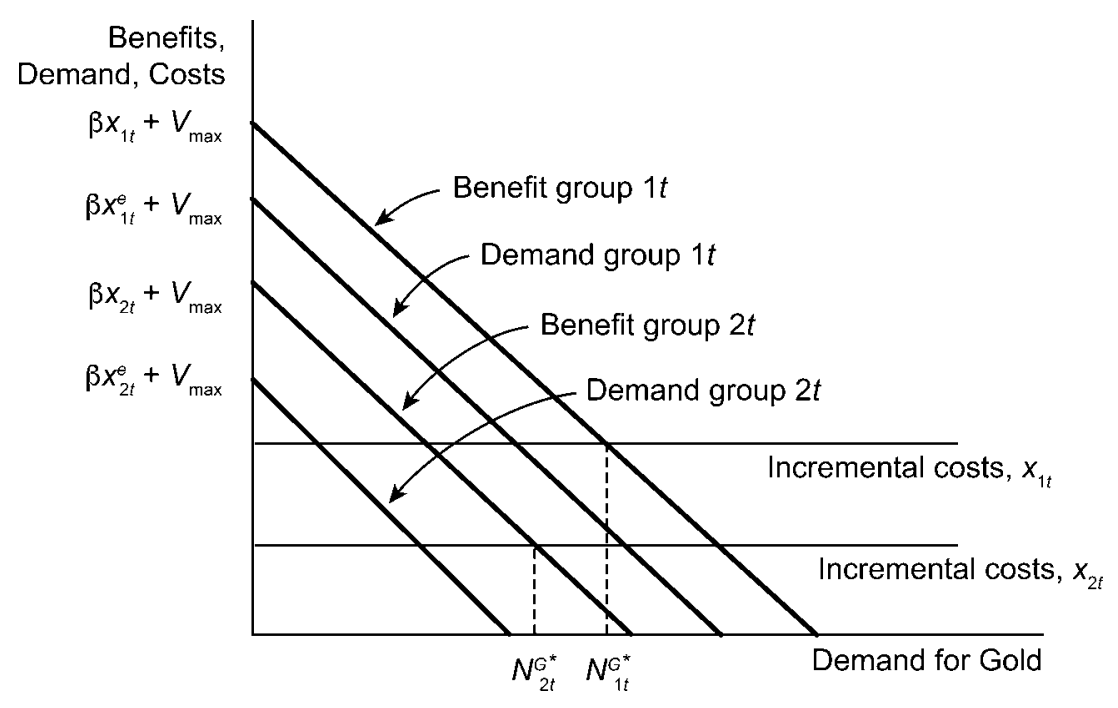

Fig. 12.3 Demand and benefit among two groups with same premium

12.3. Finally, figure 12.3 contains the incremental costs for the two groups, equal to $x_{1 t}$ and $x_{2 t}$, respectively, and the efficient memberships in Gold, $N_{1 t}^{g^{*}}$ and $N_{2 t}^{g^{*}}$.

We make several observations based on the figure. First, for any premium $p_{t}$ that the two $h$ groups have in common, more members of the more expensive group $1 t$ will join Gold than the equal-sized less expensive group $2 t$, that is, selection happens. Indeed, until the premium falls to $v_{\max }+\beta x_{2 t}^{e}$, only group $1 t$ will join. With further premium reductions, some of both groups join Gold. Since in our model both demands have slope of $\left[-1 /\left(v_{\max }-v_{\min }\right)\right]$ $N_{h t}$, at the margin the mix of joiners is 50-50, reflecting the overall mix in the $t$ category. As premium falls, the composition of the Gold joiners will move toward the mix of $h$ groups in the $t$ category, reducing the degree of selection. (This is consistent with the EF model.)

Second and importantly, no single premium will lead both groups to make the efficient decision about Gold membership. In other words, no premium can induce $N_{1 t}^{g^{*}}$ to join Gold from $1 t$ and $N_{2 t}^{g^{*}}$ to join Gold from $2 t$. This illustrates that the best premium for a $t$ group is a second best - full efficiency in plan sorting is unattainable with a single premium.

Third, the "first-best" premium for each of the two groups is not incremental marginal cost, when demand diverges from benefit. Take group $1 t$. We want $N_{1 t}^{g^{*}}$ from this group to join Gold. Setting a premium for this group to be equal to $x_{1 t}$ would not do it - too few would join Gold at that premium because health care costs are anticipated imperfectly. We have to reduce the incremental premium to below this level to "correct for" the 
underanticipation of health care costs among members of a high-cost group. ${ }^{26}$ Recognizing imperfect foresight implies that a Pigouvian correction for under- or overanticipation of benefits needs to be built into the second-best premium.

\subsection{Results}

We begin with two normative benchmarks: the (unattainable) first best in which everyone is in the best plan for them, and the (attainable) second best in which the Gold incremental premiums for each of the twelve premium categories are chosen so as to minimize welfare loss in sorting.

To implement these benchmarks, we need to make choices about the parameters describing benefits and demand. We choose parameter values for $\beta, v$ and $\gamma$ to lead to what we judge to be a reasonable degree of adverse selection between the two plan types (described shortly). In EF terms, that the incremental AC for the Gold plan is declining with lower premiums (selection happens), and cuts the demand curve from below (there is an equilibrium, no "death spiral"). In other words, the market demand and cost curves look something like figure 1 from the Einav, Finkelstein, and Cullen (2010) paper.

\subsubsection{Benchmark: First-Best Allocation}

Table 12.2 describes the first-best sorting of individuals between Silver and Gold plans for a baseline set of parameter values. We set $\beta=1.1$. The idiosyncratic term $v$ is uniform with three ranges, one for each of the three age groups. For the young, $v$ is $[-\$ 1,000, \$ 1,000]$, for the middle-age group $[-\$ 2,000, \$ 2,000]$, and for the older group $[-\$ 4,000, \$ 4,000]$, ranges roughly scaled to health care costs for the three age groups. On average, the additional services in Gold are worth their cost (since $\beta>1$ ), but not for everyone because of the idiosyncratic term. For the first best, we use rule (6) to allocate membership from each $h t$ group to the Gold plan. All persons in an $h t$ group are the same except for their idiosyncratic $v$ term. We can define a cutoff value of $v$ for each $h t$ group that defines the person whose net benefit is the same in the two plans. From equation (6):

$$
v_{h t}^{*}=(1-\beta) x_{h t} .
$$

Persons in an $h t$ group with $v_{i} \geq v_{h t}^{*}$ should be in Gold, and others in Silver. When $\beta>1, v_{h t}^{*}$ is negative, indicating that more than half of members of all $h t$ groups will be in Gold in the first best.

26. If we could set premium separately for group $1 t$ (which of course we cannot), it would be $p_{1 t}^{*}=x_{1 t}+\beta\left(x_{1 t}^{e}-x_{1 t}\right)$. The correction for imperfect foresight is the $\beta\left(x_{1 t}^{e}-x_{1 t}\right)$ term. 
First-best allocation to Silver and Gold plans

\begin{tabular}{|c|c|c|c|c|c|c|}
\hline \multirow{2}{*}{\multicolumn{3}{|c|}{ Premium categories }} & \multicolumn{2}{|c|}{ Average costs } & \multirow{2}{*}{\multicolumn{2}{|c|}{ Enrollment }} \\
\hline & & & \multirow{2}{*}{$\begin{array}{l}\text { Silver } \\
(\$)\end{array}$} & \multirow{2}{*}{$\begin{array}{l}\text { Gold } \\
(\$)\end{array}$} & & \\
\hline Age & Region & $N$ & & & Silver & Gold \\
\hline \multirow[t]{4}{*}{$19-30$} & Northeast & 2,541 & 1,273 & 1,722 & 1,236 & 1,305 \\
\hline & Midwest & 3,720 & 1,797 & 2,371 & 1,790 & 1,930 \\
\hline & South & 7,298 & 1,356 & 1,820 & 3,544 & 3,754 \\
\hline & West & 5,893 & 1,119 & 1,518 & 2,876 & 3,017 \\
\hline \multirow[t]{4}{*}{$31-50$} & Northeast & 4,167 & 2,768 & 3,538 & 2,024 & 2,143 \\
\hline & Midwest & 5,703 & 2,648 & 3,452 & 2,773 & 2,930 \\
\hline & South & 11,580 & 2,112 & 2,771 & 5,662 & 5,918 \\
\hline & West & 8,406 & 2,047 & 2,630 & 4,114 & 4,292 \\
\hline \multirow[t]{4}{*}{$51-64$} & Northeast & 2,362 & 4,474 & 5,714 & 1,154 & 1,208 \\
\hline & Midwest & 3,131 & 5,024 & 6,383 & 1,525 & 1,606 \\
\hline & South & 5,826 & 4,727 & 5,990 & 2,842 & 2,984 \\
\hline & West & 4,040 & 4,012 & 5,045 & 1,978 & 2,062 \\
\hline
\end{tabular}

The number of persons in an $h t$ group who should go to the Gold plan, $N_{h t}^{g^{*}}$, is simply the number in the group times share whose valuation exceeds $x_{h t}$, the incremental cost, or

$$
N_{h t}^{g^{*}}=N_{h t}\left[\frac{v_{\max }-v_{h t}^{*}}{v_{\max }-v_{\min }}\right]
$$

$N_{h t}^{g *}$ has a maximum value of $N_{h t}$ and a minimum of 0 . Summing over $h$ yields the values for each $t$ group in table 12.2. Table 12.2 also shows the average costs for the enrollees in the two plans for each premium group.

\subsubsection{Benchmark: Second-Best Allocation}

The second normative standard is a second best in which demands, conditioned on premiums in twelve categories, determine the allocation of people between Gold and Silver plans. One consideration in the second best is the incremental cost of Gold for a premium group. "Incremental" refers to the cost of Gold above Silver. As equation (3) makes clear, as the incremental premium changes, a mix of heterogeneous individuals within the $t$ group change plans. "Incremental cost" in this context is thus the weighted average of the incremental costs of persons choosing Gold as a function of the premium. Because there is a mix of types on the margin within a premium group, the second-best incremental premium will not be the "right" premium for each of the $h$ groups involved.

A second consideration is the distinction between demand and benefit. Generally, with imperfect foresight, individuals will not accurately predict their health care costs, and therefore not accurately predict how much they 
Table 12.3

Finding the second-best premium for the thirty-one- to fifty-year-olds in the Northeast

\begin{tabular}{lcccccc}
\hline $\begin{array}{l}\text { Incremental } \\
\text { premium } \\
\text { chosen } \\
\text { (\$) }\end{array}$ & $\begin{array}{c}\text { Enrollment } \\
\text { in Gold }\end{array}$ & $\begin{array}{c}\text { Silver } \\
(\$)\end{array}$ & $\begin{array}{c}\text { Gold } \\
\mathbf{( \$ )}\end{array}$ & $\begin{array}{c}\text { Average costs } \\
\text { average cost } \\
(\$)\end{array}$ & $\begin{array}{c}\text { Incremental } \\
\text { marginal } \\
\text { benefit } \\
(\$)\end{array}$ & $\begin{array}{c}\text { Incremental } \\
\text { marginal } \\
\text { cost } \\
(\$)\end{array}$ \\
\hline 500 & 2,180 & 2,653 & 3,660 & 1,007 & 537 & \\
$\mathbf{5 3 5}$ & $\mathbf{2 , 1 4 3}$ & $\mathbf{2 , 6 5 7}$ & $\mathbf{3 , 6 6 4}$ & $\mathbf{1 , 0 0 7}$ & $\mathbf{5 7 2}$ & $\mathbf{5 7 2}$ \\
572 & 2,105 & 2,661 & 3,669 & 1,008 & 609 & 572 \\
600 & 2,075 & 2,664 & 3,672 & 1,008 & 637 & 572 \\
700 & 1,971 & 2,673 & 3,685 & 1,012 & 737 & 572 \\
800 & 1,867 & 2,681 & 3,699 & 1,017 & 837 & 572 \\
900 & 1,763 & 2,689 & 3,714 & 1,025 & 937 & 572 \\
1,000 & 1,659 & 2,696 & 3,732 & 1,036 & 1,037 & 572 \\
1,100 & 1,555 & 2,703 & 3,752 & 1,049 & 1,137 & 572 \\
1,200 & 1,450 & 2,709 & 3,775 & 1,066 & 1,237 & 572 \\
1,300 & 1,346 & 2,715 & 3,801 & 1,087 & 1,337 & 572 \\
1,400 & 1,242 & 2,720 & 3,832 & 1,112 & 1,437 & 572 \\
1,500 & 1,138 & 2,725 & 3,869 & 1,144 & 1,537 & 572 \\
\hline
\end{tabular}

would benefit from membership in the Gold plan. In our simulations we assume $\gamma=.2$, implying that individuals put .2 weight on the actual costs of their $h t$ group with forming expectations and .8 weight on the sample mean, $\bar{x} \cdot{ }^{27}$ The second-best incremental premium is defined by the intersection of the marginal benefit schedule for a $t$ group and marginal costs.

To find the second-best allocation and premium, we trace out demand, marginal benefit, and (averaged) incremental marginal cost curves for each premium group and find their intersection, a process illustrated in table 12.3 for the thirty-one- to fifty-year-olds in the Northeast. Beginning at the bottom of the table with a high premium of $\$ 1,500$, enrollment in Gold is 1,138 out of the 4,167 people in that premium group. The table also shows costs for both plans at this premium. For those in the Gold plan at this premium the average cost is $\$ 3,869$, and $\$ 2,725$ for the balance of the people in the Silver plan. Costs differ because for any person the Gold is 20 percent more expensive, and because a different mix of people ( $h$-types) is in the two plans. Note that as the premium falls, more people move to Gold, but also the Gold average cost falls. The most expensive $h$-types within the premium group prefer the Gold at the high premium, but as the premium falls, a more representative group is joining. As the last column (incremental marginal cost) indicates, the mix of $h$-types joining the Gold plan is constant over this

27. Some researchers (e.g., Newhouse et al. 1989) have argued that about 25 percent of health care costs are predictable by individuals. We acknowledge, however, that we choose $\gamma$ for practical reasons, to make the degree of selection look "reasonable." 


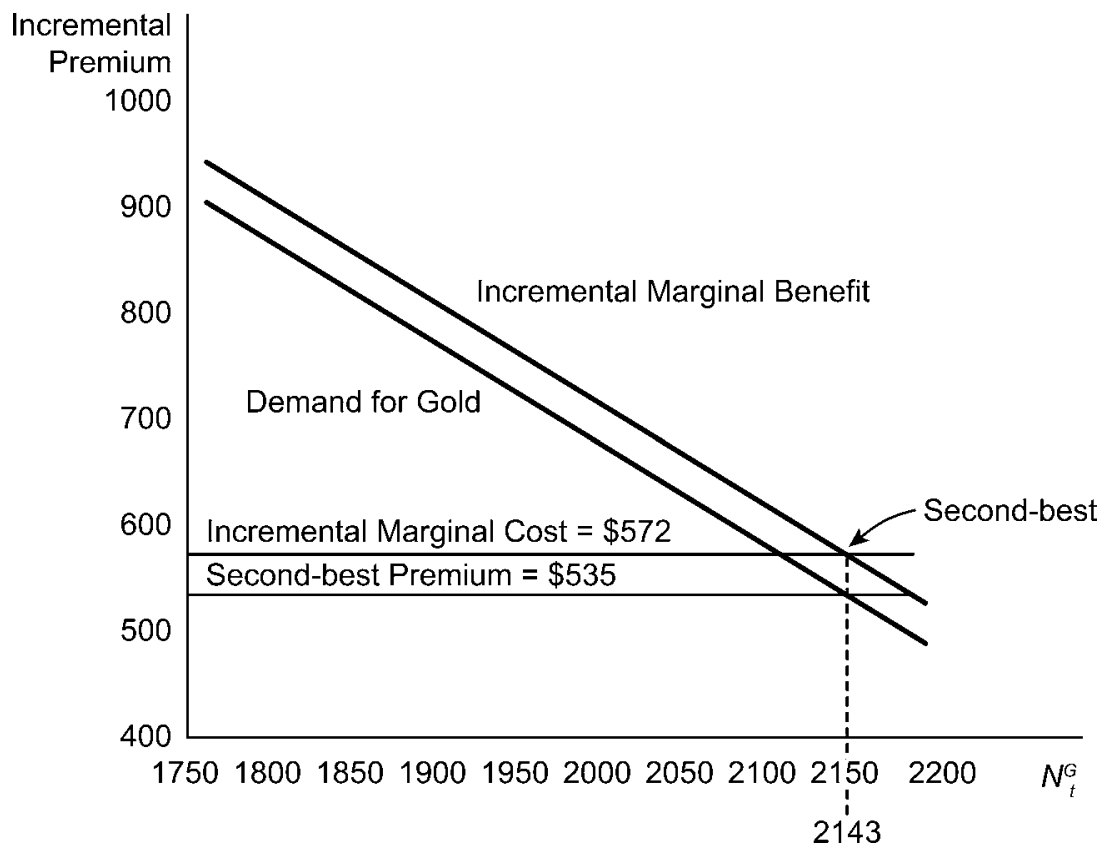

Fig. 12.4 Second-best allocation for thirty-one- to fifty-year-olds, Northeast

range of premiums. ${ }^{28}$ (At premiums much higher or lower, this would not be true.) "Incremental average cost" refers to the difference in the average cost of the Gold and the Silver plans. This falls as premium falls. In a market equilibrium, this incremental average cost needs to be covered by the incremental premium (above a premium at the Silver plan that covers average cost) at the Gold plan.

The marginal benefit schedule is constructed as follows. As incremental premium falls, we know (by demand, which depends on $x_{h t}^{e}$ ) which individuals move to the Gold plan. These individuals have a benefit (that depends on $x_{h t}$ ) from the Gold plan. The marginal benefit value in table 12.3 is these benefits averaged over the people who move for a given premium difference. Figure 12.4 plots demand, marginal benefit, incremental average, and marginal cost from table 12.3. Because marginal benefit is below demand, to induce the correct enrollment, the incremental premium charged to this group must be less than incremental marginal cost.

Table 12.4 shows the second-best enrollment and premiums for all twelve premium groups. Enrollments are in all cases very close to the enrollments in the first best. Seeing 1,305 in Gold in both the first and second best does not mean the second best is identical to the first best. The 1,305 is rounded

28. This special feature is a consequence of our assumptions. 
Table 12.4 Second-best premiums and allocation

\begin{tabular}{|c|c|c|c|c|c|c|c|}
\hline \multicolumn{3}{|c|}{ Premium categories } & \multicolumn{2}{|c|}{ Enrollment } & \multirow{2}{*}{$\begin{array}{c}\text { Incremental } \\
\text { marginal } \\
\text { cost } \\
(\$)\end{array}$} & \multirow{2}{*}{$\begin{array}{l}\text { Second- } \\
\text { best } \\
\text { premium } \\
(\$)\end{array}$} & \multirow{2}{*}{$\begin{array}{c}\text { Welfare } \\
\text { loss } \\
(\$)\end{array}$} \\
\hline Age & Region & $N$ & Silver & Gold & & & \\
\hline \multirow[t]{4}{*}{$19-30$} & Northeast & 2,541 & 1,236 & 1,305 & 271 & 499 & 0.57 \\
\hline & Midwest & 3,720 & 1,790 & 1,930 & 378 & 512 & 0.64 \\
\hline & South & 7,298 & 3,544 & 3,754 & 288 & 501 & 0.58 \\
\hline & West & 5,893 & 2,873 & 3,020 & 238 & 494 & 0.50 \\
\hline \multirow[t]{4}{*}{$31-50$} & Northeast & 4,167 & 2,024 & 2,143 & 572 & 535 & 0.65 \\
\hline & Midwest & 5,703 & 2,773 & 2,930 & 553 & 533 & 0.82 \\
\hline & South & 11,580 & 5,663 & 5,917 & 443 & 520 & 0.71 \\
\hline & West & 8,406 & 4,113 & 4,293 & 424 & 517 & 0.52 \\
\hline \multirow[t]{4}{*}{$51-64$} & Northeast & 2,362 & 1,154 & 1,208 & 924 & 577 & 1.03 \\
\hline & Midwest & 3,131 & 1,525 & 1,606 & 1,035 & 591 & 1.06 \\
\hline & South & 5,826 & 2,842 & 2,984 & 972 & 583 & 0.96 \\
\hline & West & 4,040 & 1,978 & 2,062 & 822 & 565 & 0.70 \\
\hline All & & 64,667 & 31,517 & 33,150 & $\mathrm{n} / \mathrm{a}$ & $\mathrm{n} / \mathrm{a}$ & 0.70 \\
\hline
\end{tabular}

to the nearest whole person, but more importantly, there are some wrong assignments both ways in the second best, whereas everyone is in the right plan for them in the first-best scenario. Specifically, for the nineteen- to thirty-year-olds in the NE, sixteen enrollees (1.3 percent of Silver enrollment) are in Silver who should be in Gold, and sixteen in Gold who should be in Silver. For the entire population, 359 are in Gold who should be in Silver and 358 are in Silver who should be in Gold, amounting to slightly over 1 percent of the population. ${ }^{29}$

The last column in table 12.4 shows the average welfare loss per person for each group and overall associated with being in the "wrong" plan. In the first best, everyone in an $h t$ group with a value of $v>v_{h t}^{*}$ should be in Gold. By contrast, in the second best, where individuals respond to a premium, although that premium is set at the most efficient level for the $t$ group, it will not be efficient for each of the $h$ groups within the premium category. In the second best, everyone with a $v>v_{h t}^{\text {2nd-best }}$ will choose Gold where this cutoff for each $h t$ group in the second best where

$$
v_{h t}^{2 \text { nd-best }}=p_{t}^{2 \text { nd-best }}-\beta x_{h t}^{e} .
$$

Thus, within each $h t$ group there is a range of individuals between $v_{h t}^{*}$ and $v_{h t}^{\text {2nd-best }}$ who are in the "wrong" plan. For some $h$ groups $v_{h t}^{*}>v_{h t}^{\text {nd-best }}$ and for others the reverse will be true. To see how we calculate welfare loss for

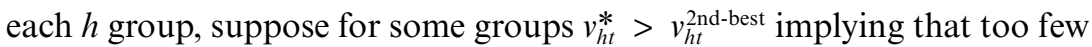
people from this group are in the Gold plan. The measure of inefficiency for

29. These numbers are not shown in the table, and are rounded to the nearest "whole person." 
this $h$ group is the probability that someone in the group is in the wrong plan times the average lost benefit for the person wrongly located.

Avg Welfare Loss for $h t$ group in Second-Best $=\left[\frac{v_{h t}^{*}-v_{h t}^{2 \text { nd-best }}}{v_{\max }-v_{\min }}\right]\left[\frac{v_{h t}^{*}-v_{h t}^{2 \text { nd-best }}}{2}\right]$.

The first term of this product is the probability that a person is in the range of $v$ where the person is in the wrong plan; the second term is the average of the lowest (0) and highest $\left(v_{h t}^{*}-v_{h t}^{\text {2nd-best }}\right)$ value of the net benefit lost from being in the wrong plan. ${ }^{30}$

Averaged over the entire population, this comes out to only $\$ 0.70$ per person, the minimum welfare loss that can be attained given these premium groups. The welfare loss in the second best also depends on the benefits in the two plan types and on the nature of individuals' expectations about their costs. The adverse selection problem would be aggravated, and the welfare loss higher, if individuals could forecast more accurately than we have assumed here in these simulations.

The second-best allocation depends only on the incremental premium charged enrollees for Gold. Silver and Gold plans must, of course, break even in an equilibrium. This consideration introduces another set of factors that will determine how much more people are charged to join Gold: the difference between the break-even premium for the Silver plan and for the Gold plan. This will not, of course, in general, be the second best. We move now to consideration of a series of market equilibria: no risk adjustment, conventional risk adjustment, and risk adjustment to hit the second-best premiums. In all equilibria considered, premium for each category for the Silver and Gold plans will be equal to average cost in that premium category.

\subsubsection{Equilibrium with No Risk Adjustment}

In equilibrium, premium for the Silver plan must equal Silver plan average costs, premium for the Gold plan equals Gold plan average costs, and the difference between these, the incremental premium that consumers face, must sort individuals such that the resulting plan average costs are covered by the premiums. We find the equilibrium by tracing out demand and cost curves.

The equilibrium is depicted graphically in figure 12.5 for the thirty-oneto fifty-year-olds in the Northeast. Figure 12.5 augments figure 12.4 with a lower quadrant showing the average costs for both plans..$^{31}$ The incremental average cost in the upper quadrant is seen to be the difference between the average cost curves from the lower quadrant. The lower quadrants can also

30. Thus, a kind of "Harberger triangle."

31. In the textbook EF model, the "other plan" has zero costs and zero premium for any enrollee. When the other plan is a real plan, its costs too will vary as enrollment changes in the Gold plan. 


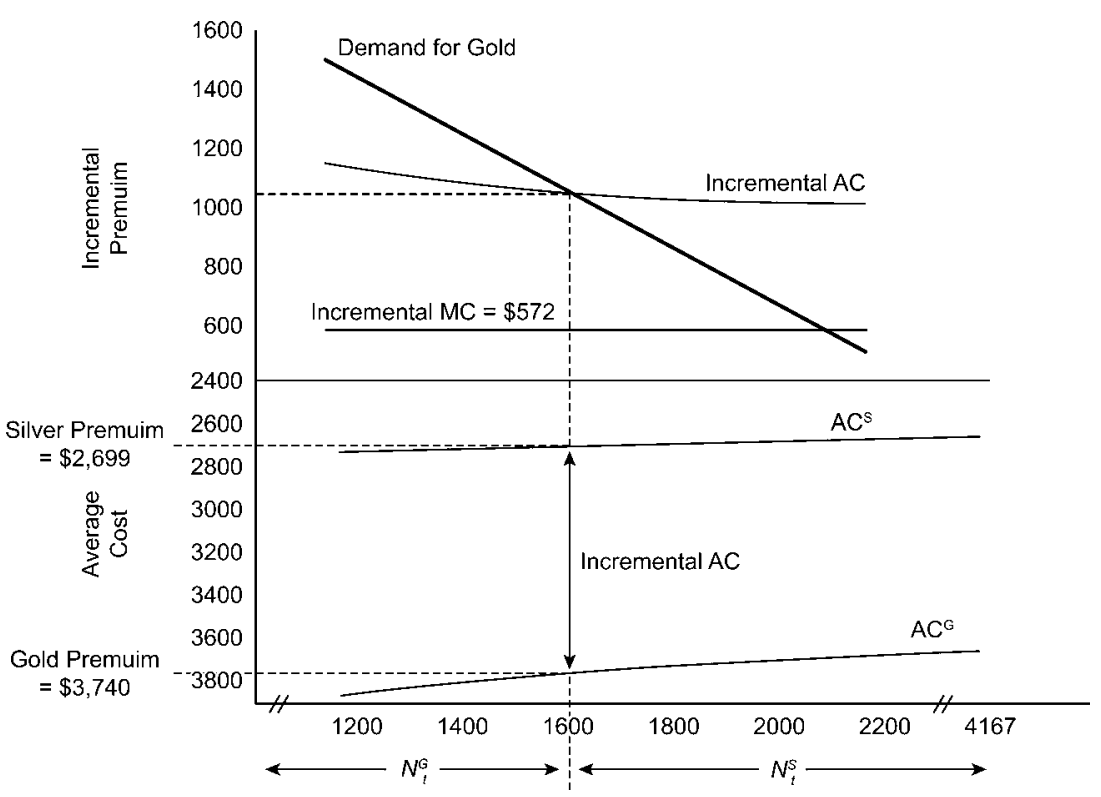

Fig. 12.5 EF equilibrium with no risk adjustment, thirty-one- to fifty-year-olds, Northeast

be used to depict the equilibrium premiums in both the Gold and Silver plans.

Results are summarized for all twelve premium categories in table 12.5. Fewer enrollees are in Gold because for all premium categories, premiums to cover average costs are "too high" in relation to either the first or second best. Instead of more than half of people in Gold in the second best, only 40 percent $(26,044 / 64,667)$ are in Gold in the equilibrium without risk adjustment. Note that as in the second best, there will be enrollment mistakes in both directions, though with equilibrium premiums too high, most of the mistakes will be putting too many people in Silver. The welfare loss in this equilibrium is much greater than the second best. On average, as the last column in table 12.5 shows, the welfare loss is $\$ 32.25$ per person.

Beginning with this first equilibrium, we can keep track of how well the payment system - here just premiums - fits costs for Gold and Silver plans. By "fit" we mean the degree to which variation in revenue per person tracks costs per person. To figure fit we generalize the concept of statistical fit to account for both premiums and risk adjustment of plan payments. For each individual, we construct a measure of total payments to the plan (i.e., plan revenues), including the premium and risk adjustment. This value is then 
Table 12.5

Equilibrium premiums and allocation without risk adjustment

\begin{tabular}{|c|c|c|c|c|c|c|c|c|}
\hline \multirow{2}{*}{\multicolumn{3}{|c|}{ Premium categories }} & \multirow{2}{*}{\multicolumn{2}{|c|}{ Enrollment }} & \multicolumn{3}{|c|}{ Premiums } & \multirow{3}{*}{$\begin{array}{c}\text { Welfare } \\
\text { loss } \\
(\$)\end{array}$} \\
\hline & & & & & \multirow{2}{*}{$\begin{array}{l}\text { Silver } \\
\text { (\$) }\end{array}$} & \multirow{2}{*}{$\begin{array}{l}\text { Gold } \\
(\$)\end{array}$} & \multirow{2}{*}{$\begin{array}{l}\text { Incremental } \\
\text { (\$) }\end{array}$} & \\
\hline Age & Region & $N$ & Silver & Gold & & & & \\
\hline \multirow[t]{4}{*}{$19-30$} & Northeast & 2,541 & 1,465 & 1,076 & 1,202 & 1,881 & 679 & 8.69 \\
\hline & Midwest & 3,720 & 2,467 & 1,253 & 1,742 & 2,617 & 876 & 33.81 \\
\hline & South & 7,298 & 4,245 & 3,053 & 1,287 & 1,980 & 693 & 9.80 \\
\hline & West & 5,893 & 3,165 & 2,728 & 1,046 & 1,639 & 593 & 2.91 \\
\hline \multirow[t]{4}{*}{$31-50$} & Northeast & 4,167 & 2,551 & 1,616 & 2,699 & 3,740 & 1,041 & 32.65 \\
\hline & Midwest & 5,703 & 3,684 & 2,019 & 2,571 & 3,743 & 1,172 & 51.90 \\
\hline & South & 11,580 & 6,899 & 4,681 & 2,030 & 2,978 & 947 & 23.55 \\
\hline & West & 8,406 & 4,666 & 3,740 & 1,979 & 2,758 & 780 & 9.14 \\
\hline \multirow[t]{4}{*}{$51-64$} & Northeast & 2,362 & 1,479 & 883 & 4,370 & 6,049 & 1,679 & 76.89 \\
\hline & Midwest & 3,131 & 2,010 & 1,121 & 4,923 & 6,753 & 1,830 & 97.06 \\
\hline & South & 5,826 & 3,635 & 2,191 & 4,629 & 6,300 & 1,672 & 75.06 \\
\hline & West & 4,040 & 2,357 & 1,683 & 3,927 & 5,240 & 1,314 & 35.76 \\
\hline All & & 64,667 & 38,623 & 26,044 & $\mathrm{n} / \mathrm{a}$ & $\mathrm{n} / \mathrm{a}$ & $\mathrm{n} / \mathrm{a}$ & 32.25 \\
\hline
\end{tabular}

compared with the individual's costs to construct our fit measure. ${ }^{32}$ Specifically, let $R_{i}$ be the total revenue a plan receives for person $i$ after risk adjustment, and $x_{i}$ be the total costs for person $i$. Total variation in Silver plan costs is $\Sigma_{i}\left(x_{i}^{s}-\overline{x^{s}}\right)^{2}$, where $\overline{x^{s}}$ is the mean plan cost and the summation is over individuals in the Silver plan. Variation remaining after the payment system is $\Sigma_{i}\left(x_{i}^{s}-R_{i}\right)^{2}$. Thus, the $R$-squared or "fit" of the payment system for Silver is

$$
\text { Payment system fit for Silver }=1-\frac{\sum_{i}\left(x_{i}^{s}-R_{i}\right)^{2}}{\sum_{i}\left(x_{i}^{s}-\overline{x^{s}}\right)^{2}} \text {. }
$$

A similar expression characterizes fit in the Gold plan.

Plan revenues in the current simulation are simply the premiums covering average cost for each premium group. Some "risk adjustment" is accomplished by premium categories. Values for payment system fit are 0.019 for both Silver and Gold in the no risk-adjustment case.

\subsubsection{Equilibrium with Conventional Risk Adjustment}

Conventional risk adjustment is based on the regression from table 12A.2. Conventional risk adjustment is estimated ex ante, before plans set premi-

32. There are other plausible measures of fit, such as the mean absolute difference between revenues and costs. Not squaring this difference down weights the influence of high-cost outliers in the fit measure. We chose the payment system $R$-squared to be easily comparable to statistics reported for risk adjustment, and on the general principle in economics that the economic value of a loss goes up approximately with the square of the difference between the actual and the optimal price. 
Table 12.6

Equilibrium premiums and allocation with conventional risk adjustment

\begin{tabular}{|c|c|c|c|c|c|c|c|c|}
\hline \multirow{2}{*}{\multicolumn{3}{|c|}{ Premium categories }} & \multirow{2}{*}{\multicolumn{2}{|c|}{ Enrollment }} & \multicolumn{3}{|c|}{ Premiums } & \multirow{3}{*}{$\begin{array}{c}\text { Welfare } \\
\text { loss } \\
(\$)\end{array}$} \\
\hline & & & & & \multirow{2}{*}{$\begin{array}{l}\text { Silver } \\
(\$)\end{array}$} & \multirow{2}{*}{$\begin{array}{l}\text { Gold } \\
(\$)\end{array}$} & \multirow{2}{*}{$\begin{array}{l}\text { Incremental } \\
(\$)\end{array}$} & \\
\hline Age & Region & $N$ & Silver & Gold & & & & \\
\hline \multirow[t]{4}{*}{$19-30$} & Northeast & 2,541 & 981 & 1,560 & 2,572 & 2,870 & 298 & 10.58 \\
\hline & Midwest & 3,720 & 1,602 & 2,118 & 2,944 & 3,355 & 411 & 3.17 \\
\hline & South & 7,298 & 2,866 & 4,432 & 2,595 & 2,910 & 315 & 9.19 \\
\hline & West & 5,893 & 2,190 & 3,703 & 2,452 & 2,714 & 262 & 14.01 \\
\hline \multirow[t]{4}{*}{$31-50$} & Northeast & 4,167 & 2,102 & 2,065 & 3,074 & 3,684 & 610 & 1.35 \\
\hline & Midwest & 5,703 & 2,870 & 2,833 & 2,842 & 3,444 & 601 & 1.40 \\
\hline & South & 11,580 & 5,553 & 6,027 & 2,418 & 2,900 & 482 & 0.89 \\
\hline & West & 8,406 & 3,979 & 4,427 & 2,582 & 3,034 & 453 & 1.03 \\
\hline \multirow[t]{4}{*}{$51-64$} & Northeast & 2,362 & 1,276 & 1,086 & 2,662 & 3,652 & 990 & 11.67 \\
\hline & Midwest & 3,131 & 1,726 & 1,405 & 2,954 & 4,058 & 1,105 & 17.60 \\
\hline & South & 5,826 & 3,171 & 2,655 & 2,673 & 3,707 & 1,034 & 13.66 \\
\hline & West & 4,040 & 2,130 & 1,910 & 2,617 & 3,482 & 865 & 6.32 \\
\hline All & & 64,667 & 30,446 & 34,221 & $\mathrm{n} / \mathrm{a}$ & $\mathrm{n} / \mathrm{a}$ & $\mathrm{n} / \mathrm{a}$ & 6.32 \\
\hline
\end{tabular}

ums and before individuals choose plans. The demand curve for Gold membership is unaffected by risk adjustment. Risk adjustment affects the costs that must be covered by premiums at the two plans because the risk-adjusted revenues now vary according to the personal characteristics of the joiners. Therefore, the incremental average cost that describes the difference in the premiums for Gold and Silver for any premium group also changes. Risk adjustment takes from each plan (either Gold or Silver) the average cost at the Silver plan, $\bar{x}^{s}$, and returns to each plan the risk-adjusted payment $r_{h}$ estimate from a regression on Silver plan costs (from table 12A.2 in the appendix). (This risk-adjustment system is self-financing, but the amount "taken" from the plans does not affect the equilibrium so long as the amount is constant for both plan types - it only affects the level of premiums in the two plans.) We compute average cost at the Gold and Silver plans net of risk-adjustment transfers then the average incremental cost for the Gold plan. Equilibrium is, as before, where the incremental premium at the Gold plan equals this risk-adjusted average incremental cost.

Concurrent conventional risk adjustment imposes the market equilibrium compared to that with no risk adjustment, as shown in table 12.6. Equilibrium premiums are much reduced, and many more people move to Gold. This is consistent with the objective of risk adjustment: by transferring funds to more costly individuals, selection has less effect on the net average cost of the plans. (If risk adjustment were perfect and fully picked up expected costs, the mix of joiners would have no effect at all on plans' average costs.) Incremental premiums for the young groups are below the second-best premiums, and for the older groups they are above. Risk adjustment can deal 
with correcting premiums for selection; it cannot deal at all, at least directly, with correcting for over- or underanticipation of costs. The welfare loss per person in conventional risk adjustment falls to $\$ 6.32$ per person.

Furthermore, conventional risk adjustment improves the fit of the payment system for both plans. For the Silver plans the payment system fit rises to .168 and to .164 for the Gold plans.

\subsubsection{Risk Adjustment to Achieve the Second Best}

In our final set of simulations, we find risk-adjustment weights incorporating constraints to ensure that the equilibrium premium is the second-best incremental premium. Consider the first premium group, the nineteen- to thirty-year-olds living in the Northeast. Call them premium group 1. With conventional risk adjustment, table 12.6 tells us that the equilibrium incremental premium is too low, $\$ 298$ instead of the second-best $\$ 499$, and too many from this group are in the Gold plan in the conventional risk-adjustment equilibrium. The constraint that premium for the nineteen- to thirty-year-olds in the NE is $\$ 499$ in equilibrium comes from the expressions that the Silver and Gold plan premiums for this group must be zero profit. For the Silver plan, premium for group 1 is the cost for the group less the net risk-adjustment transfer:

$$
p_{1}^{s}=\frac{\sum_{h} N_{h 1}^{s} \mathrm{X}_{h 1}^{s}}{\sum_{h} N_{h 1}^{s}}-\frac{\sum_{h} r_{h} N_{h 1}^{s}}{\sum_{h} N_{h 1}^{s}}+\bar{x} .
$$

Expressing the Gold premium as the Silver premium $+\$ 499$ (the desired incremental premium), the breakeven condition for the Gold plan for group 1 is:

$$
p_{1}^{s}+499=\frac{\sum_{h} N_{h h}^{g} x_{h 1}^{g}}{\sum_{h} N_{h 1}^{g}}-\frac{\sum_{h} r_{h} N_{h 1}^{g}}{\sum_{h} N_{h 1}^{g}}+\bar{x} .
$$

Substituting for the Silver premium and canceling the overall average costs, we have:

$$
499=\frac{\sum_{h} N_{h 1}^{g} X_{h 1}^{g}}{\sum_{h} N_{h 1}^{g}}-\frac{\sum_{h} N_{h}^{s} \mathbf{X}_{h 1}^{s}}{\sum_{h} N_{h 1}^{s}}+\frac{\sum_{h} r_{h} N_{h 1}^{s}}{\sum_{h} N_{h 1}^{s}}-\frac{\sum_{h} r_{h} N_{h 1}^{g}}{\sum_{h} N_{h 1}^{g}} .
$$

The $\$ 499$ has to cover the difference in the average costs between the two plans (the first two terms in equation [11]), less any higher risk-adjustment transfers to Gold.

Having solved for the second best, we know average cost in the Silver and Gold plan in the second best, and the enrollments in those plans in the second best. The only "variables" in equation (11) are the risk-adjustment weights. Thus, equation (11) is linear in the $r_{h}$ weights, and forms the constraint corresponding to the restriction that the incremental premium for the nineteen- to thirty-year-olds is the second best in equilibrium.

After reproducing the conventional risk-adjustment equilibrium results in the first pair of columns, table 12.7, in the second pair of columns, shows 
the equilibrium with a risk-adjustment system estimated by imposing the one constraint, equation (11) from above. Specifically, we estimate a conventional concurrent risk-adjustment model, identical to the one contained in table 12A.2 from the appendix and described above, but with the constraint that the risk-adjustment weights satisfy equation (11). This regression, and the regressions with more constraints are also contained in table 12A.2. With new risk-adjustment weights, there will be a new equilibrium for all premium categories. Table 12.7 shows the full set of results. Equilibrium incremental premiums generally move in the right direction (toward the second best) for all the young premium categories as the result of imposing the single constraint for the young NE group. The welfare cost per person for all four of the young groups fall as this one constraint comes into play. In aggregate, the sorting between Gold and Silver becomes more efficient, with the per-person welfare loss dropping from $\$ 6.32$ to $\$ 4.75$ per person..$^{33}$

Improvement in sorting efficiency comes at a cost in terms of "fit" of the payment system to the Gold and Silver plan. With one constraint, the payment system fit in the Silver and Gold plans fall from 0.168 and 0.164 with conventional risk adjustment to 0.155 and 0.149 , respectively. Fit statistics are summarized for our equilibrium cases in figure 12.6.

Table 12.7 and figure 12.6 also contain the results for risk-adjustment systems in which we include two and three constraints. Our two-constraint model imposes, in addition to equation (11) above, a constraint that the premium for the thirty-one- to fifty-year-olds in the NE must be equal to $\$ 535$, the second-best incremental premium for this group. The form of the constraint is analogous to equation (11). Welfare loss from sorting falls for the middle groups and for the overall average for the population to $\$ 3.24$. Fit deteriorates for both the Silver and Gold plans. Finally, we also impose a constraint on the fifty-one- to sixty-four-year-olds in the NE, making three constraints in total, bringing down welfare loss to $\$ 2.17$ per person, but leading to payment-system fits for the Silver and Gold plans of 0.081 and 0.117 , respectively.

In principle, we could impose more than three constraints on the secondbest premium. To attain the full second best, we could impose all twelve premium constraints. In fact, we have done this in results not reported. We found that the constrained risk-adjustment regressions yielded unreasonable coefficient estimates on the HCC indicators (i.e., too large or too small), and furthermore, the plan-fit measures became very poor. We believe the instability and unreasonableness of the estimates would be relieved with a much larger sample size. In an exchange population, a relatively small share of the population has any positive HCC indicator. ${ }^{34}$ Calibration of the

33. Because we are imposing just one constraint, there is no guarantee that the average welfare loss falls.

34. Only about 20 percent of the people in our exchange population have any HCC. 


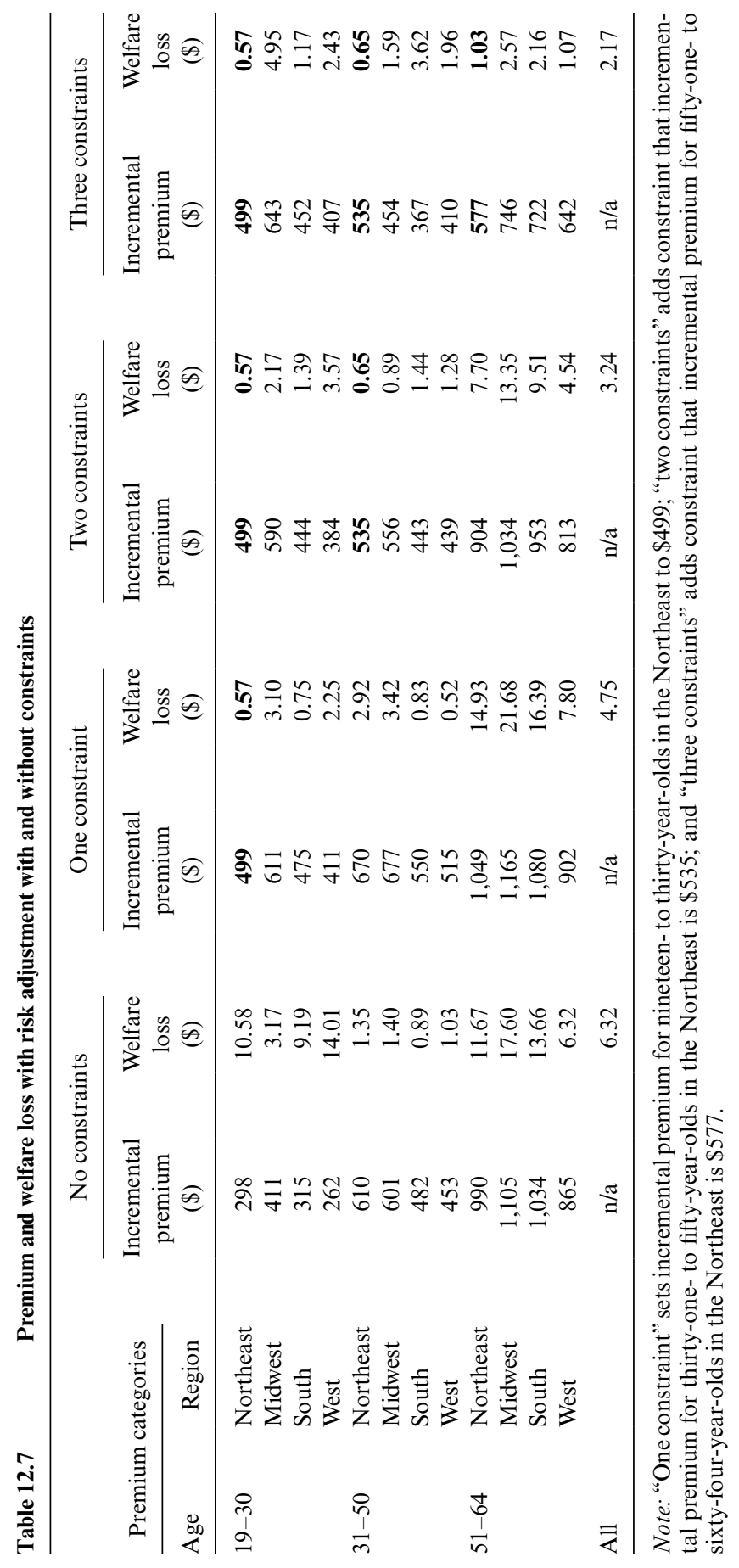




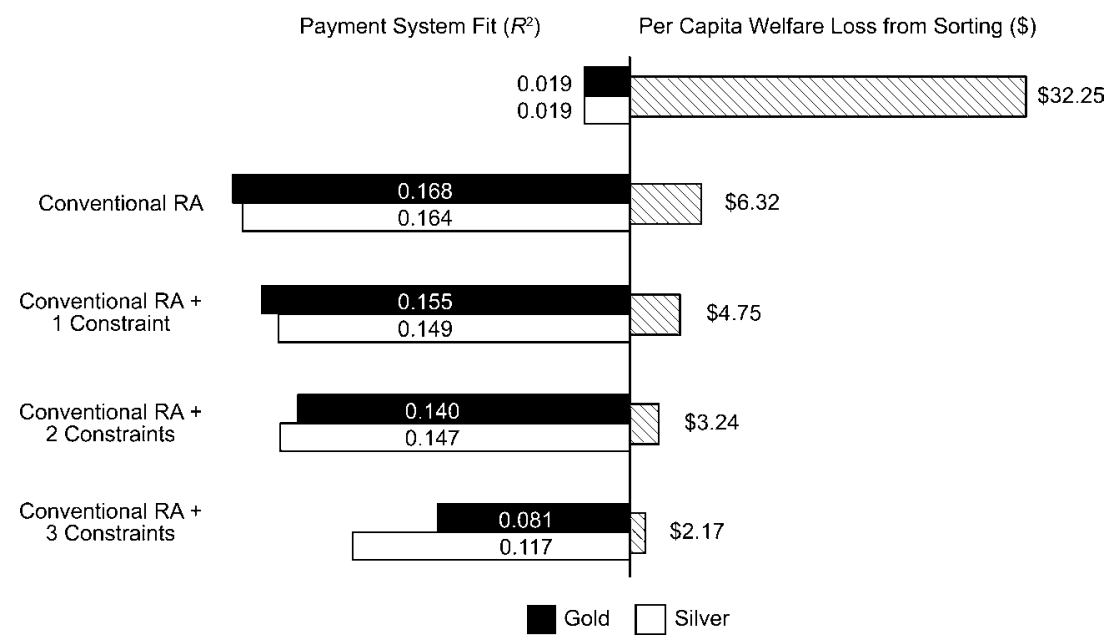

Fig. 12.6 Payment system fit and sorting efficiency trade-off

trade-off between sorting efficiency and plan fit should be next done with the much larger data sets actually used for risk adjustment.

\subsection{Discussion}

Our goal in this chapter is to introduce risk adjustment - a supply-side policy - into the analysis of EF-type adverse selection stemming from a pricing problem on the demand side due to consumers not facing the correct incremental price for the more generous plan. Risk adjustment can be helpful because it affects the equilibrium incremental premium. We show how this works, and how to incorporate the goal of efficient sorting between plan types into consideration of setting risk adjustment weights.

Our chapter contains theoretical extensions of the EF model and an empirical implementation. The empirical analysis involves a number of assumptions that we acknowledge here. Although we made an effort to capture important features of payment systems in exchanges, including the predominant risk-adjustment methodology, our results can only be regarded as illustrative, due to data limitations as well as many features of exchanges (such as more than two plan types, more detailed risk-adjustment categories, reinsurance and risk corridors, and others) that we could not incorporate in our simulations.

In this final section we would like to call attention to the major conceptual points in the chapter and make some comments about application of the ideas. At the most general level, we want to stress that the connection between premiums and risk adjustment is one that affects welfare outcomes. How plans are paid for various enrollees must affect equilibrium market premiums, no matter what market structure governs plan competition. Pre- 
miums are important for plan sorting and even consumer participation in exchanges, and are therefore important to consider in risk adjustment.

To anticipate the impact of risk adjustment on premiums accurately requires a conception (a model) of how premiums are set and how risk adjustment affects costs a plan must cover with the premium. Heterogeneity in a population is central to this issue. The EF-type models already incorporate some heterogeneity in demand and cost, but the textbook EF model needs elaboration for the task of incorporating risk adjustment. Principally, it is necessary to recognize payments to plans depend on the risk score of their enrollees. Groups defined on another but related dimension will pay different premiums for plans. These generalizations of the EF framework when taken to data involve many steps that we take in the chapter. The main conceptual points to take away from these generalizations are, however, straightforward:

- No single premium will sort a population efficiently between two plans. While this point has been made in the health economics literature, the textbook EF diagram makes it look like a single premium can eliminate the "welfare cost" of adverse selection.

- As a corollary, when there is more than one group in a population, the area between the demand curve in aggregate and the marginal cost curve in the EF diagram is not an accurate measure of the welfare loss at all. With multiple groups, the marginal cost curve in that picture is an average marginal cost.

There are two primary welfare frameworks for evaluating the functioning of private health insurance markets, a utility-based framework, and a demand-cost framework. Most papers in the literature use one or the other. For example, EF uses demand and cost. Our chapter uses both, starting with utility and deriving the demand and marginal benefit schedule. Doing so explicitly is a reminder of the assumptions necessary to go from utility to demand. Major assumptions have to do with what a consumer "knows" or can forecast, and the degree to which consumers are fully rational. It is very unclear the degree to which demand (willingness to pay) can serve as a welfare framework in health insurance. While ultimately utility is the gold standard for welfare in economics, demand and cost diagrams are the workhorses of applied welfare economics. An important agenda item for health economics and policy is coming up with a practical and valid method for normative analysis of health insurance markets.

It is worth recalling in this respect that the EF approach treats plan characteristics as fixed, missing an important efficiency concern, dating from some of the first research on the economics of insurance market equilibrium, about how selection influences the design of the health insurance product itself (Rothschild and Stiglitz 1976). Einav-Finkelstein, as well as the work we do here, does not incorporate equity considerations. The basic EF framework with one group and one premium is not suited to healthy-sick or other cross-group comparisons. In the current chapter, because we have 
age groups and risk adjustment, it would be possible to do more with equity. Interestingly, our efficiency corrections tend to level age-group differences among equilibrium premiums.

One of the practical applications of the methods developed here is to address questions around determination of population groups with respect to premium categories. A great deal of research has focused on the question of grouping people for purposes of risk adjustment. Risk-adjustment statistical models are generally populated with $(0,1)$ variables that correspond to risk-adjustment cells. Much less work has been directed to the question of what are the right premium groups. We know one group is inefficient and two groups could improve the efficiency of sorting, but the introduction of groups implies different premiums for the different groups that may introduce fairness issues. In order to evaluate any efficiency-fairness trade-off, we need to have a sense of what the efficiency gains are for dividing a population more finely. The methods here help to address the issue.

In addition to contributions that depend on welfare or evaluation of efficiency, we have shown here how to work with the connection between premiums and risk adjustment. If a regulator is interested in premium targets (e.g., keeping premiums for young people below some level), risk adjustment can be the tool to hit the targets by adding premium constraints to the riskadjustment formulas.

\section{Appendix}

Table 12A.1 Changes on the algorithm from ICD-9 codes to CMS-HCCs

\begin{tabular}{ll}
\hline $\begin{array}{l}\text { ICD-9 } \\
\text { codes }\end{array}$ & \multicolumn{1}{c}{ CCs } \\
$650-659$ & Five pregnancy-related CCs are added: \\
$640-649$ & 201 Complications mainly related to pregnancy \\
$660-669$ & 202 Complications occurring mainly in the course of labor \\
$670-677$ & 203 Complications of the puerperium \\
$630-639$ & 204 Ectopic and molar pregnancy \\
HCC108 (Chronic obstructive pulmonary disease) is broken into two CCs: \\
210 Chronic obstructive pulmonary disease, except asthma \\
211 Asthma \\
HCC 176 (Artificial openings for feeding or elimination) is broken into three CCs: \\
220 Diseases of esophagus \\
221 Disorders of function of stomach \\
222 Other disorders of intestine
\end{tabular}

Notes: The CCs are sorted as 200, 201, 202, 203, and 204 from least to most severe conditions. Individuals are assigned to the most severe code for hierarchy adjustment if they have multiple conditions. 


\begin{tabular}{|c|c|c|c|c|c|}
\hline & $\begin{array}{l}\text { Conventional } \\
\text { risk } \\
\text { adjustment }\end{array}$ & $\begin{array}{l}\text { Conventional } \\
\text { RA plus } 1 \\
\text { constraint }\end{array}$ & $\begin{array}{l}\text { Conventional } \\
\text { RA plus } 2 \\
\text { constraints }\end{array}$ & $\begin{array}{l}\text { Conventional } \\
\text { RA plus } 3 \\
\text { constraints }\end{array}$ & $\begin{array}{c}\text { Conventional } \\
\text { RA plus } \\
\text { premium } \\
\text { categories }\end{array}$ \\
\hline F18_24 & $\begin{array}{c}1,234 \\
(120)\end{array}$ & $\begin{array}{c}979 \\
(120)\end{array}$ & $\begin{array}{c}618 \\
(121)\end{array}$ & $\begin{array}{c}739 \\
(125)\end{array}$ & $\begin{array}{c}1,189 \\
(192)\end{array}$ \\
\hline F25_34 & $\begin{array}{r}1,686 \\
(96)\end{array}$ & $\begin{array}{r}1,044 \\
(94)\end{array}$ & $\begin{array}{l}516 \\
(94)\end{array}$ & $\begin{array}{l}481 \\
(97)\end{array}$ & $\begin{array}{r}1,580 \\
(186)\end{array}$ \\
\hline F35_44 & $\begin{array}{r}1,504 \\
(96)\end{array}$ & $\begin{array}{r}1,756 \\
(97)\end{array}$ & $\begin{array}{r}1,741 \\
(98)\end{array}$ & $\begin{array}{r}1,195 \\
(101)\end{array}$ & $\begin{array}{c}1,275 \\
(223)\end{array}$ \\
\hline F45_54 & $\begin{array}{r}1,695 \\
(95)\end{array}$ & $\begin{array}{r}1,906 \\
(96)\end{array}$ & $\begin{array}{l}1,803 \\
(96)\end{array}$ & $\begin{array}{l}630 \\
(98)\end{array}$ & $\begin{array}{c}1,358 \\
(228)\end{array}$ \\
\hline F55_64 & $\begin{array}{r}2,236 \\
(120)\end{array}$ & $\begin{array}{l}2,488 \\
(121)\end{array}$ & $\begin{array}{l}1,714 \\
(119)\end{array}$ & $\begin{array}{c}1,470 \\
(123)\end{array}$ & $\begin{array}{c}1,713 \\
(271)\end{array}$ \\
\hline M18_24 & $\begin{array}{c}387 \\
(111)\end{array}$ & $\begin{array}{c}1,653 \\
(104)\end{array}$ & $\begin{array}{c}2,213 \\
(103)\end{array}$ & $\begin{array}{r}2,146 \\
(107)\end{array}$ & $\begin{array}{c}349 \\
(184)\end{array}$ \\
\hline M25_34 & $\begin{array}{l}582 \\
(90)\end{array}$ & $\begin{array}{r}1,064 \\
(90)\end{array}$ & $\begin{array}{l}802 \\
(90)\end{array}$ & $\begin{array}{r}1,428 \\
(93)\end{array}$ & $\begin{array}{c}463 \\
(183)\end{array}$ \\
\hline M35_44 & $\begin{array}{l}853 \\
(93)\end{array}$ & $\begin{array}{l}962 \\
(94)\end{array}$ & $\begin{array}{l}149 \\
(91)\end{array}$ & $\begin{array}{r}1,112 \\
(93)\end{array}$ & $\begin{array}{l}625 \\
(222)\end{array}$ \\
\hline M45_54 & $\begin{array}{r}1,490 \\
(99)\end{array}$ & $\begin{array}{r}1,632 \\
(99)\end{array}$ & $\begin{array}{c}1,496 \\
(100)\end{array}$ & $\begin{array}{c}47 \\
(101)\end{array}$ & $\begin{array}{c}1,146 \\
(230)\end{array}$ \\
\hline M55_64 & $\begin{array}{l}2,106 \\
(122)\end{array}$ & $\begin{array}{l}2,303 \\
(123)\end{array}$ & $\begin{array}{l}1,626 \\
(122)\end{array}$ & $\begin{array}{c}971 \\
(126)\end{array}$ & $\begin{array}{l}1,586 \\
(272)\end{array}$ \\
\hline $\mathrm{HCCl}$ & $\begin{array}{c}3,235 \\
(445)\end{array}$ & $\begin{array}{c}1,525 \\
(445)\end{array}$ & $\begin{array}{c}1,553 \\
(449)\end{array}$ & $\begin{array}{c}987 \\
(464)\end{array}$ & $\begin{array}{c}3,228 \\
(445)\end{array}$ \\
\hline $\mathrm{HCC} 2$ & $\begin{array}{c}2,161 \\
(495)\end{array}$ & $\begin{array}{l}-396 \\
(492)\end{array}$ & $\begin{array}{r}-1,650 \\
(495)\end{array}$ & $\begin{array}{r}-2,058 \\
(512)\end{array}$ & $\begin{array}{c}2,165 \\
(495)\end{array}$ \\
\hline HCC5 & $\begin{array}{c}1,859 \\
(311)\end{array}$ & $\begin{array}{c}1,056 \\
(312)\end{array}$ & $\begin{array}{c}1,491 \\
(314)\end{array}$ & $\begin{array}{l}-219 \\
(324)\end{array}$ & $\begin{array}{r}1,833 \\
(311)\end{array}$ \\
\hline $\mathrm{HCC} 7$ & $\begin{array}{r}13,565 \\
(885)\end{array}$ & $\begin{array}{r}14,010 \\
(892)\end{array}$ & $\begin{array}{r}17,368 \\
(894)\end{array}$ & $\begin{array}{r}32,757 \\
(893)\end{array}$ & $\begin{array}{r}13,559 \\
(885)\end{array}$ \\
\hline HCC8 & $\begin{array}{l}13,666 \\
(1,186)\end{array}$ & $\begin{array}{l}14,094 \\
(1,195)\end{array}$ & $\begin{array}{l}18,132 \\
(1,199)\end{array}$ & $\begin{array}{l}30,940 \\
(1,225)\end{array}$ & $\begin{array}{l}13,653 \\
(1,186)\end{array}$ \\
\hline HCC9 & $\begin{array}{r}17,992 \\
(870)\end{array}$ & $\begin{array}{r}13,660 \\
(865)\end{array}$ & $\begin{array}{r}15,212 \\
(871)\end{array}$ & $\begin{array}{r}16,436 \\
(901)\end{array}$ & $\begin{array}{r}17,972 \\
(869)\end{array}$ \\
\hline $\mathrm{HCC} 10$ & $\begin{array}{c}5,526 \\
(242)\end{array}$ & $\begin{array}{c}5,171 \\
(243)\end{array}$ & $\begin{array}{c}6,846 \\
(240)\end{array}$ & $\begin{array}{c}7,592 \\
(248)\end{array}$ & $\begin{array}{c}5,510 \\
(242)\end{array}$ \\
\hline HCC19 & $\begin{array}{c}3,423 \\
(146)\end{array}$ & $\begin{array}{l}3,423 \\
(147)\end{array}$ & $\begin{array}{r}4,226 \\
(146)\end{array}$ & $\begin{array}{l}5,701 \\
(149)\end{array}$ & $\begin{array}{c}3,422 \\
(146)\end{array}$ \\
\hline HCC26 & $\begin{array}{c}1,724 \\
(1,226)\end{array}$ & $\begin{array}{c}1,728 \\
(1,235)\end{array}$ & $\begin{array}{c}-17 \\
(1,244)\end{array}$ & $\begin{array}{c}3,768 \\
(1,285)\end{array}$ & $\begin{array}{c}1,738 \\
(1,225)\end{array}$ \\
\hline $\mathrm{HCC} 27$ & $\begin{array}{c}6,104 \\
(856)\end{array}$ & $\begin{array}{c}6,665 \\
(862)\end{array}$ & $\begin{array}{r}11,523 \\
(857)\end{array}$ & $\begin{array}{r}13,455 \\
(886)\end{array}$ & $\begin{array}{c}6,092 \\
(856)\end{array}$ \\
\hline HCC31 & $\begin{array}{r}4,399 \\
(610)\end{array}$ & $\begin{array}{r}4,280 \\
(615)\end{array}$ & $\begin{array}{r}4,477 \\
(620)\end{array}$ & $\begin{array}{r}2,706 \\
(641)\end{array}$ & $\begin{array}{r}4,415 \\
(610)\end{array}$ \\
\hline HCC32 & $\begin{array}{r}10,740 \\
(874)\end{array}$ & $\begin{array}{c}6,514 \\
(870)\end{array}$ & $\begin{array}{l}5,654 \\
(877)\end{array}$ & $\begin{array}{c}9,902 \\
(904)\end{array}$ & $\begin{array}{r}10,746 \\
(874)\end{array}$ \\
\hline HCC33 & $\begin{array}{c}5,085 \\
(752)\end{array}$ & $\begin{array}{c}4,394 \\
(757)\end{array}$ & $\begin{array}{c}7,602 \\
(758)\end{array}$ & $\begin{array}{c}1,892 \\
(779)\end{array}$ & $\begin{array}{c}5,053 \\
(752) \\
\text { (continued) }\end{array}$ \\
\hline
\end{tabular}




\begin{tabular}{|c|c|c|c|c|c|}
\hline & $\begin{array}{c}\text { Conventional } \\
\text { risk } \\
\text { adjustment }\end{array}$ & $\begin{array}{l}\text { Conventional } \\
\text { RA plus } 1 \\
\text { constraint }\end{array}$ & $\begin{array}{l}\text { Conventional } \\
\text { RA plus } 2 \\
\text { constraints }\end{array}$ & $\begin{array}{l}\text { Conventional } \\
\text { RA plus } 3 \\
\text { constraints }\end{array}$ & $\begin{array}{l}\text { Conventional } \\
\text { RA plus } \\
\text { premium } \\
\text { categories }\end{array}$ \\
\hline HCC 37 & $\begin{array}{c}3,188 \\
(353)\end{array}$ & $\begin{array}{c}3,064 \\
(356)\end{array}$ & $\begin{array}{c}4,221 \\
(357)\end{array}$ & $\begin{array}{c}3,237 \\
(369)\end{array}$ & $\begin{array}{c}3,181 \\
(353)\end{array}$ \\
\hline HCC 38 & $\begin{array}{c}2,521 \\
(309)\end{array}$ & $\begin{array}{c}2,426 \\
(312)\end{array}$ & $\begin{array}{c}3,182 \\
(314)\end{array}$ & $\begin{array}{c}3,510 \\
(324)\end{array}$ & $\begin{array}{r}2,498 \\
(309)\end{array}$ \\
\hline $\mathrm{HCC} 44$ & $\begin{array}{c}4,382 \\
(772)\end{array}$ & $\begin{array}{c}1,836 \\
(773)\end{array}$ & $\begin{array}{c}1,445 \\
(780)\end{array}$ & $\begin{array}{c}8,343 \\
(799)\end{array}$ & $\begin{array}{r}4,384 \\
(772)\end{array}$ \\
\hline HCC45 & $\begin{array}{l}13,615 \\
(1,157)\end{array}$ & $\begin{array}{l}10,627 \\
(1,162)\end{array}$ & $\begin{array}{l}18,130 \\
(1,150)\end{array}$ & $\begin{array}{l}18,234 \\
(1,189)\end{array}$ & $\begin{array}{l}13,596 \\
(1,157)\end{array}$ \\
\hline HCC52 & $\begin{array}{r}4,125 \\
(845)\end{array}$ & $\begin{array}{c}1,814 \\
(848)\end{array}$ & $\begin{array}{r}1,552 \\
(856)\end{array}$ & $\begin{array}{c}-285 \\
(884)\end{array}$ & $\begin{array}{c}4,101 \\
(845)\end{array}$ \\
\hline HCC54 & $\begin{array}{c}9,373 \\
(1,039)\end{array}$ & $\begin{array}{c}7,504 \\
(1,045)\end{array}$ & $\begin{array}{c}9,759 \\
(1,052)\end{array}$ & $\begin{array}{l}10,135 \\
(1,088)\end{array}$ & $\begin{array}{c}9,408 \\
(1,039)\end{array}$ \\
\hline HCC55 & $\begin{array}{c}4,691 \\
(423)\end{array}$ & $\begin{array}{r}1,619 \\
(414)\end{array}$ & $\begin{array}{r}2,839 \\
(416)\end{array}$ & $\begin{array}{r}-2,409 \\
(422)\end{array}$ & $\begin{array}{c}4,666 \\
(423)\end{array}$ \\
\hline HCC69 & $\begin{array}{c}2,610 \\
(1,160)\end{array}$ & $\begin{array}{c}867 \\
(1,167)\end{array}$ & $\begin{array}{c}-591 \\
(1,177)\end{array}$ & $\begin{array}{c}-34 \\
(1,217)\end{array}$ & $\begin{array}{c}2,629 \\
(1,160)\end{array}$ \\
\hline HCC71 & $\begin{array}{c}5,693 \\
(1,242)\end{array}$ & $\begin{array}{c}6,608 \\
(1,251)\end{array}$ & $\begin{array}{c}8,959 \\
(1,260)\end{array}$ & $\begin{array}{c}7,238 \\
(1,303)\end{array}$ & $\begin{array}{c}5,628 \\
(1,242)\end{array}$ \\
\hline HCC72 & $\begin{array}{l}17,470 \\
(1,005)\end{array}$ & $\begin{array}{r}11,637 \\
(995)\end{array}$ & $\begin{array}{r}17,896 \\
(986)\end{array}$ & $\begin{array}{c}23,631 \\
(1,016)\end{array}$ & $\begin{array}{l}17,483 \\
(1,005)\end{array}$ \\
\hline $\mathrm{HCC} 73$ & $\begin{array}{r}2,308 \\
(600)\end{array}$ & $\begin{array}{r}2,912 \\
(604)\end{array}$ & $\begin{array}{r}3,039 \\
(609)\end{array}$ & $\begin{array}{r}6,759 \\
(627)\end{array}$ & $\begin{array}{r}2,268 \\
(600)\end{array}$ \\
\hline $\mathrm{HCC} 74$ & $\begin{array}{c}3,811 \\
(762)\end{array}$ & $\begin{array}{c}2,021 \\
(765)\end{array}$ & $\begin{array}{r}2,206 \\
(772)\end{array}$ & $\begin{array}{r}2,137 \\
(798)\end{array}$ & $\begin{array}{c}3,783 \\
(762)\end{array}$ \\
\hline HCC75 & $\begin{array}{c}4,761 \\
(1,283)\end{array}$ & $\begin{array}{c}4,211 \\
(1,292)\end{array}$ & $\begin{array}{c}3,744 \\
(1,304)\end{array}$ & $\begin{array}{l}12,631 \\
(1,341)\end{array}$ & $\begin{array}{c}4,665 \\
(1,283)\end{array}$ \\
\hline $\mathrm{HCC} 77$ & $\begin{array}{r}3,309 \\
(618)\end{array}$ & $\begin{array}{r}3,359 \\
(623)\end{array}$ & $\begin{array}{c}4,212 \\
(628)\end{array}$ & $\begin{array}{r}5,694 \\
(649)\end{array}$ & $\begin{array}{r}3,302 \\
(618)\end{array}$ \\
\hline HCC79 & $\begin{array}{c}4,219 \\
(840)\end{array}$ & $\begin{array}{c}4,457 \\
(846)\end{array}$ & $\begin{array}{c}6,112 \\
(852)\end{array}$ & $\begin{array}{c}3,250 \\
(880)\end{array}$ & $\begin{array}{c}4,193 \\
(840)\end{array}$ \\
\hline HCC 80 & $\begin{array}{c}5,689 \\
(362)\end{array}$ & $\begin{array}{c}5,132 \\
(364)\end{array}$ & $\begin{array}{c}5,239 \\
(367)\end{array}$ & $\begin{array}{c}9,801 \\
(373)\end{array}$ & $\begin{array}{c}5,689 \\
(362)\end{array}$ \\
\hline HCC82 & $\begin{array}{r}12,477 \\
(463)\end{array}$ & $\begin{array}{r}12,748 \\
(467)\end{array}$ & $\begin{array}{r}13,539 \\
(470)\end{array}$ & $\begin{array}{r}21,898 \\
\quad(469)\end{array}$ & $\begin{array}{r}12,459 \\
(463)\end{array}$ \\
\hline $\mathrm{HCC} 83$ & $\begin{array}{r}3,175 \\
(640)\end{array}$ & $\begin{array}{r}3,575 \\
(645)\end{array}$ & $\begin{array}{r}3,935 \\
(650)\end{array}$ & $\begin{array}{r}10,243 \\
(665)\end{array}$ & $\begin{array}{r}3,169 \\
(640)\end{array}$ \\
\hline HCC92 & $\begin{array}{c}3,943 \\
(418)\end{array}$ & $\begin{array}{c}3,638 \\
(421)\end{array}$ & $\begin{array}{r}4,446 \\
(424)\end{array}$ & $\begin{array}{c}6,567 \\
(437)\end{array}$ & $\begin{array}{c}3,921 \\
(418)\end{array}$ \\
\hline НCC96 & $\begin{array}{r}10,126 \\
(601)\end{array}$ & $\begin{array}{c}9,283 \\
(605)\end{array}$ & $\begin{array}{r}10,383 \\
(609)\end{array}$ & $\begin{array}{r}18,664 \\
(617)\end{array}$ & $\begin{array}{r}10,141 \\
(601)\end{array}$ \\
\hline $\mathrm{HCC} 104$ & $\begin{array}{c}5,493 \\
(315)\end{array}$ & $\begin{array}{c}5,401 \\
(317)\end{array}$ & $\begin{array}{r}7,983 \\
(310)\end{array}$ & $\begin{array}{c}6,390 \\
(320)\end{array}$ & $\begin{array}{c}5,486 \\
(315)\end{array}$ \\
\hline HCC105 & $\begin{array}{r}12,741 \\
(639)\end{array}$ & $\begin{array}{r}10,681 \\
(640)\end{array}$ & $\begin{array}{r}16,124 \\
(625)\end{array}$ & $\begin{array}{r}16,048 \\
(646)\end{array}$ & $\begin{array}{r}12,727 \\
(639)\end{array}$ \\
\hline HCC119 & $\begin{array}{c}3,332 \\
(404)\end{array}$ & $\begin{array}{r}2,721 \\
(407)\end{array}$ & $\begin{array}{r}3,132 \\
(410)\end{array}$ & $\begin{array}{r}2,878 \\
(424)\end{array}$ & $\begin{array}{c}3,323 \\
(404)\end{array}$ \\
\hline
\end{tabular}




\begin{tabular}{|c|c|c|c|c|c|}
\hline & $\begin{array}{c}\text { Conventional } \\
\text { risk } \\
\text { adjustment }\end{array}$ & $\begin{array}{l}\text { Conventional } \\
\text { RA plus } 1 \\
\text { constraint }\end{array}$ & $\begin{array}{l}\text { Conventional } \\
\text { RA plus } 2 \\
\text { constraints }\end{array}$ & $\begin{array}{l}\text { Conventional } \\
\text { RA plus } 3 \\
\text { constraints }\end{array}$ & $\begin{array}{l}\text { Conventional } \\
\text { RA plus } \\
\text { premium } \\
\text { categories }\end{array}$ \\
\hline $\mathrm{HCC} 130$ & $\begin{array}{l}11,775 \\
(1,059)\end{array}$ & $\begin{array}{c}8,768 \\
(1,062)\end{array}$ & $\begin{array}{c}6,748 \\
(1,069)\end{array}$ & $\begin{array}{c}28,180 \\
(1,055)\end{array}$ & $\begin{array}{l}11,752 \\
(1,058)\end{array}$ \\
\hline HCC131 & $\begin{array}{r}19,239 \\
(870)\end{array}$ & $\begin{array}{r}17,584 \\
(875)\end{array}$ & $\begin{array}{r}20,490 \\
(878)\end{array}$ & $\begin{array}{r}25,724 \\
(905)\end{array}$ & $\begin{array}{r}19,213 \\
(870)\end{array}$ \\
\hline HCC148 & $\begin{array}{c}5,553 \\
(677)\end{array}$ & $\begin{array}{r}5,115 \\
(682)\end{array}$ & $\begin{array}{r}6,969 \\
(686)\end{array}$ & $\begin{array}{r}3,552 \\
(707)\end{array}$ & $\begin{array}{c}5,542 \\
(677)\end{array}$ \\
\hline $\mathrm{HCC} 155$ & $\begin{array}{c}3,652 \\
(581)\end{array}$ & $\begin{array}{c}610 \\
(576)\end{array}$ & $\begin{array}{l}-90 \\
(581)\end{array}$ & $\begin{array}{c}-377 \\
(601)\end{array}$ & $\begin{array}{c}3,638 \\
(581)\end{array}$ \\
\hline HCC157 & $\begin{array}{c}2,426 \\
(291)\end{array}$ & $\begin{array}{c}2,648 \\
(293)\end{array}$ & $\begin{array}{c}3,360 \\
(294)\end{array}$ & $\begin{array}{c}4,350 \\
(304)\end{array}$ & $\begin{array}{c}2,403 \\
(291)\end{array}$ \\
\hline HCC158 & $\begin{array}{l}10,164 \\
(1,133)\end{array}$ & $\begin{array}{c}8,106 \\
(1,140)\end{array}$ & $\begin{array}{l}10,103 \\
(1,148)\end{array}$ & $\begin{array}{c}9,323 \\
(1,187)\end{array}$ & $\begin{array}{l}10,171 \\
(1,133)\end{array}$ \\
\hline HCC164 & $\begin{array}{r}9,777 \\
(647)\end{array}$ & $\begin{array}{c}7,578 \\
(647)\end{array}$ & $\begin{array}{r}10,176 \\
(648)\end{array}$ & $\begin{array}{r}17,833 \\
(660)\end{array}$ & $\begin{array}{r}9,767 \\
(646)\end{array}$ \\
\hline $\mathrm{HCC} 174$ & $\begin{array}{c}7,067 \\
(1,482)\end{array}$ & $\begin{array}{c}7,526 \\
(1,493)\end{array}$ & $\begin{array}{c}9,599 \\
(1,504)\end{array}$ & $\begin{array}{c}26,982 \\
(1,532)\end{array}$ & $\begin{array}{c}7,045 \\
(1,482)\end{array}$ \\
\hline $\mathrm{HCC} 177$ & $\begin{array}{c}3,154 \\
(975)\end{array}$ & $\begin{array}{c}3,404 \\
(982)\end{array}$ & $\begin{array}{c}3,877 \\
(990)\end{array}$ & $\begin{array}{l}12,066 \\
(1,016)\end{array}$ & $\begin{array}{c}3,145 \\
(974)\end{array}$ \\
\hline HCC200 & $\begin{array}{c}6,328 \\
(754)\end{array}$ & $\begin{array}{c}-368 \\
(728)\end{array}$ & $\begin{array}{r}-2,848 \\
(730)\end{array}$ & $\begin{array}{r}-4,376 \\
(755)\end{array}$ & $\begin{array}{r}6,354 \\
(754)\end{array}$ \\
\hline HCC201 & $\begin{array}{c}5,686 \\
(689)\end{array}$ & $\begin{array}{c}3,693 \\
(691)\end{array}$ & $\begin{array}{c}4,600 \\
(696)\end{array}$ & $\begin{array}{c}991 \\
(718)\end{array}$ & $\begin{array}{c}5,671 \\
(689)\end{array}$ \\
\hline HCC202 & $\begin{array}{r}11,055 \\
(901)\end{array}$ & $\begin{array}{r}-1,929 \\
(804)\end{array}$ & $\begin{array}{r}-6,509 \\
(799)\end{array}$ & $\begin{array}{r}-9,379 \\
(825)\end{array}$ & $\begin{array}{r}11,038 \\
(901)\end{array}$ \\
\hline HCC203 & $\begin{array}{c}4,815 \\
(1,588)\end{array}$ & $\begin{array}{c}6,179 \\
(1,600)\end{array}$ & $\begin{array}{l}12,491 \\
(1,602)\end{array}$ & $\begin{array}{c}2,168 \\
(1,649)\end{array}$ & $\begin{array}{c}4,808 \\
(1,588)\end{array}$ \\
\hline HCC204 & $\begin{array}{c}1,658 \\
(674)\end{array}$ & $\begin{array}{c}-839 \\
(674)\end{array}$ & $\begin{array}{r}-2,059 \\
(679)\end{array}$ & $\begin{array}{r}-1,987 \\
(702)\end{array}$ & $\begin{array}{c}1,680 \\
(674)\end{array}$ \\
\hline HCC 210 & $\begin{array}{c}4,423 \\
(347)\end{array}$ & $\begin{array}{c}4,772 \\
(350)\end{array}$ & $\begin{array}{c}5,789 \\
(351)\end{array}$ & $\begin{array}{r}11,528 \\
(352)\end{array}$ & $\begin{array}{r}4,407 \\
(347)\end{array}$ \\
\hline HCC211 & $\begin{array}{c}1,742 \\
(204)\end{array}$ & $\begin{array}{c}1,121 \\
(205)\end{array}$ & $\begin{array}{r}2,025 \\
(205)\end{array}$ & $\begin{array}{l}221 \\
(210)\end{array}$ & $\begin{array}{c}1,705 \\
(204)\end{array}$ \\
\hline HCC220 & $\begin{array}{c}3,442 \\
(177)\end{array}$ & $\begin{array}{c}3,251 \\
(178)\end{array}$ & $\begin{array}{c}4,612 \\
(175)\end{array}$ & $\begin{array}{c}4,261 \\
(181)\end{array}$ & $\begin{array}{c}3,429 \\
(177)\end{array}$ \\
\hline HCC221 & $\begin{array}{c}2,729 \\
(300)\end{array}$ & $\begin{array}{c}1,766 \\
(301)\end{array}$ & $\begin{array}{c}1,854 \\
(303)\end{array}$ & $\begin{array}{c}2,571 \\
(314)\end{array}$ & $\begin{array}{c}2,733 \\
(300)\end{array}$ \\
\hline HCC222 & $\begin{array}{c}5,297 \\
(665)\end{array}$ & $\begin{array}{c}4,662 \\
(669)\end{array}$ & $\begin{array}{r}6,597 \\
(673)\end{array}$ & $\begin{array}{c}8,292 \\
(695)\end{array}$ & $\begin{array}{c}5,275 \\
(664)\end{array}$ \\
\hline small_hcc & $\begin{array}{c}5,968 \\
(951)\end{array}$ & $\begin{array}{c}6,565 \\
(958)\end{array}$ & $\begin{array}{c}19,033 \\
(891)\end{array}$ & $\begin{array}{r}-1,637 \\
(864)\end{array}$ & $\begin{array}{c}5,939 \\
(951)\end{array}$ \\
\hline $\begin{array}{l}\text { Restriction } \\
\text { (Young_Northeast) }\end{array}$ & & $\begin{array}{l}-3 E+08 \\
(1 E+07)\end{array}$ & $\begin{array}{l}-5 E+08 \\
(1 E+07)\end{array}$ & $\begin{array}{l}-5 E+08 \\
(1 E+07)\end{array}$ & \\
\hline $\begin{array}{l}\text { Restriction } \\
\quad \text { (Mid_Northeast) }\end{array}$ & & & $\begin{array}{c}6 \mathrm{E}+08 \\
(2 \mathrm{E}+07)\end{array}$ & $\begin{array}{l}-4 \mathrm{E}+08 \\
(2 \mathrm{E}+07)\end{array}$ & \\
\hline $\begin{array}{l}\text { Restriction } \\
\quad \text { (Old_Northeast) }\end{array}$ & & & & $\begin{array}{l}9.4 \mathrm{E}+08 \\
(1 \mathrm{E}+07)\end{array}$ & \\
\hline
\end{tabular}




\begin{tabular}{|c|c|c|c|c|c|}
\hline & $\begin{array}{l}\text { Conventional } \\
\text { risk } \\
\text { adjustment }\end{array}$ & $\begin{array}{l}\text { Conventional } \\
\text { RA plus } 1 \\
\text { constraint }\end{array}$ & $\begin{array}{l}\text { Conventional } \\
\text { RA plus } 2 \\
\text { constraints }\end{array}$ & $\begin{array}{l}\text { Conventional } \\
\text { RA plus } 3 \\
\text { constraints }\end{array}$ & $\begin{array}{c}\text { Conventional } \\
\text { RA plus } \\
\text { premium } \\
\text { categories }\end{array}$ \\
\hline Young_Midwest & & & & & $\begin{array}{c}375 \\
(208)\end{array}$ \\
\hline Young_South & & & & & $\begin{array}{c}24 \\
(186)\end{array}$ \\
\hline Young_West & & & & & $\begin{array}{c}-119 \\
(192)\end{array}$ \\
\hline Mid_Northeast & & & & & $\begin{array}{c}673 \\
(234)\end{array}$ \\
\hline Mid_Midwest & & & & & $\begin{array}{c}439 \\
(223)\end{array}$ \\
\hline Mid_South & & & & & $\begin{array}{c}12 \\
(210)\end{array}$ \\
\hline Mid_West & & & & & $\begin{array}{c}173 \\
(214)\end{array}$ \\
\hline Old_Northeast & & & & & $\begin{array}{c}479 \\
(289)\end{array}$ \\
\hline Old_Midwest & & & & & $\begin{array}{c}770 \\
(259)\end{array}$ \\
\hline Old_South & & & & & $\begin{array}{c}489 \\
(259)\end{array}$ \\
\hline Old_West & & & & & $\begin{array}{c}430 \\
(267)\end{array}$ \\
\hline$R^{2}$ & 0.236 & 0.224 & 0.211 & 0.156 & 0.236 \\
\hline
\end{tabular}

Source: MEPS, 2004-2010.

Note: All dollar estimates reported in 2010 USD, and standard errors are shown in parentheses. $N=$ 64,667 .

\section{References}

Abaluck, J., and J. Gruber. 2011. "Choice Inconsistencies among the Elderly: Evidence from Plan Choice in the Medicare Part D Program." American Economic Review 101 (4): 1180-210.

Agency for Healthcare Research and Quality (AHRQ). 2008. MEPS HC-092 19962004 Risk Adjustment Scores, Public Use File. Rockville, MD: AHRQ. 2011. MEPS HC-128: Medical Conditions File. Rockville, MD: AHRQ.

Aizcorbe, A., E. Liebman, S. Pack, D. M. Cutler, M. E. Chernew, and A. B. Rosen. 2012. "Measuring Health Care Costs of Individuals with Employer-Sponsored Health Insurance in the US: A Comparison of Survey and Claims Data." Bureau of Economic Analysis 28:43-51. http://www.bea.gov/papers/pdf/Measuring\%20health $\% 20$ care $\% 20 \operatorname{costs}^{\circ} \% 20$ of $\% 20$ individuals $\% 20$ with $\% 20$ employer-sponsored $\% 20$ health $\% 20$ insurance.pdf.

Akerlof, G. A. 1970. "The Market for 'Lemons': Quality Uncertainty and the Market Mechanism.” Quarterly Journal of Economics 84 (3): 488-500. 
Bundorf, M. K., J. D. Levin, and N. Mahoney. 2012. "Pricing and Welfare in Health Plan Choice." American Economic Review 102 (7): 3214-48.

Carlin, C., and R. Town. 2010. "Adverse Selection, Welfare and Optimal Pricing of Employer Sponsored Health Plans." Unpublished Manuscript.

Congressional Budget Office (CBO). 2011. CBO's Analysis of the Major Health Care Legislation Enacted in March 2010. Testimony by Douglas W. Elmendorf before the Subcommittee on Health, Committee on Energy and Commerce, US House of Representatives, March 30, 2011.

Cutler, D., G. Lincoln, and R. Zeckhauser. 2010. "Selection Stories: Understanding Movement across Health Plans.” Journal of Health Economics 29 (6): 821-38.

Cutler, D., and S. Reber. 1998. "Paying for Health Insurance: The Trade-off between Competition and Adverse Selection." Quarterly Journal of Economics 113 (2): 433-66.

Dafny, L., K. Ho, and M. Varela. 2013. "Let them Have Choice: Gains from Shifting away from Employer-Sponsored Health Insurance and Toward an Individual Exchange.” American Economic Journal: Economic Policy 5 (1): 32-58.

Department of Health and Human Services, Patient Protection and Affordable Care Act. 2013. "HHS Notice of Benefit and Payment Parameters for 2014." Federal Register 2013:15410-541.

Einav, L., and A. Finkelstein. 2011. "Selection in Insurance Markets: Theory and Empirics in Pictures." Journal of Economic Perspectives 25 (1): 115-38.

Einav, L., A. Finkelstein, and M. Cullen. 2010. "Estimating Welfare in Insurance Markets Using Variation in Prices." Quarterly Journal of Economics 125 (3): 877-921.

Einav, L., A. Finkelstein, and Levin. 2010. "Beyond Testing: Empirical Models of Insurance Markets." Annual Review of Economics 2:311-36.

Geruso, M. 2012. "Selection in Employer Health Plans: Homogeneous Prices and Heterogeneous Preferences." Unpublished Manuscript.

Glazer, J., and T. G. McGuire. 2000. "Optimal Risk Adjustment of Health Insurance Premiums: An Application to Managed Care." American Economic Review 90 (4): 1055-71.

_. 2011. "Gold and Silver Plans: Accommodating Demand Heterogeneity in Managed Competition." Journal of Health Economics 30 (5): 1011-19.

Handel, B. 2013. "Adverse Selection and Inertia in Health Insurance Markets: When Nudging Hurts.” American Economic Review 103 (7): 2643-82.

Handel, B., I. Hendel, and M. D. Whinston. 2013. "Equilibria in Health Exchanges: Adverse Selection vs. Reclassification Risk.” NBER Working Paper no. 19399, Cambridge, MA.

Keeler, E., G. Carter, and J. Newhouse. 1998. "A Model of the Impact of Reimbursement Schemes on Health Plan Choice." Journal of Health Economics 17 (3): 297-320.

Kolstad, J., and A. Kowalski. 2014. "Mandate-Based Health Reform and Evidence from the Labor Market: Evidence from the Massachusetts Reform." NBER Working Paper no. 17933, Cambridge, MA.

Lucarelli, C., J. Prince, and K. Simon. 2012. "The Welfare Impact of Reducing Choice in Medicare Part D: A Comparison of Two Regulation Strategies." International Economic Review 53 (4): 1155-77.

Lustig, J. 2008. "The Welfare Effects of Adverse Selection in Privatized Medicare." Unpublished Manuscript.

McGuire, T. G., J. Glazer, J. P. Newhouse, S.-L. Normand, J. Shi, A. D. Sinaiko, and S. Zuvekas. 2013. "Integrating Risk Adjustment and Enrollee Premiums in Health Plan Payment.” Journal of Health Economics 32 (6): 1263-77. 
Newhouse, J. P., W. G. Manning, E. B. Keeler, and E. M. Sloss. 1989. "Adjusting Capitation Rates Using Objective Health Measures and Prior Utilization." Health Care Financing Review 10 (3): 41-54.

Pope, G. C., J. Kautter, M. J. Ingber, S. Freeman, R. Sekar, and C. Newhart. 2011. "Evaluation of the CMS-HCC Risk Adjustment Model." Final Report, RTI Project no. 0209853.006, RTI International. March.

Rothschild, M., and J. Stiglitz. 1976. "Equilibrium in Competitive Insurance Markets: An Essay on the Economics of Imperfect Information." Quarterly Journal of Economics 90 (4): 629-49.

Sing, M., J. S. Banthin, T. M. Selden, C. A. Cowan, and S. P. Keehan. 2006. "Reconciling Medical Expenditure Estimates from the MEPS and NHEA, 2002." Health Care Finance Review 28 (1): 25-40.

Spinnewijn, J. 2017. "Heterogeneity, Demand for Insurance and Adverse Selection." American Economic Journal: Economic Policy 9 (1): 308-43.

Trish, E., A. Damico, G. Claxton, L. Levitt, and R. Garfield. 2011. A Profile of Health Insurance Exchange Enrollees. Kaiser Family Foundation. March. http:// kff.org/health-reform/report/a-profile-of-health-insurance-exchange-enrollees/.

Van de Ven, W. P. M. M., and R. P. Ellis. 2000. "Risk Adjustment in Competitive Health Plan Markets." In Handbook of Health Economics, vol. 1, edited by A. Culyer and J. Newhouse, 755-846. Amsterdam: Elsevier.

Zhu, J. M., T. J. Layton, A. D. Sinaiko, and T. G. McGuire. 2013. "The Power of Reinsurance in Health Insurance Exchanges to Improve the Fit of the Payment System and Reduce Incentives for Adverse Selection.” Inquiry 50 (4): 255-74.

Zuvekas, S. H., and G. Olin. 2009. "An Examination of the Accuracy of Medicare Expenditures in the Medical Expenditure Panel Survey." Inquiry 46 (1): 92-108. 